\title{
Failure Mechanisms of Mechanically and Thermally Produced Holes in High-Strength Low-Alloy Steel Plates Subjected to Fatigue Loading
}

\author{
Carlos Jiménez-Peña ${ }^{1, *(D)}$, Constantinos Goulas ${ }^{2,3} \mathbb{C}^{\mathbb{C}}$, Johannes Preußner ${ }^{4}$ \\ and Dimitri Debruyne ${ }^{1}$ \\ 1 Department of Materials Engineering, KU Leuven, Kasteelpark Arenberg 44, 3001 Leuven, Belgium; \\ dimitri.debruyne@kuleuven.be \\ 2 Department of Materials Science and Engineering, Delft University of Technology, Mekelweg 2, \\ 2628CD Delft, The Netherlands; K.Goulas@tudelft.nl \\ 3 Rotterdam Fieldlab Additive Manufacturing (RAMLAB), Scheepsbouwweg 8, \\ 3089JW Rotterdam, The Netherlands \\ 4 Fraunhofer Institute for Mechanics of Materials IWM, Wöhlerstr. 11, 79108 Freiburg, Germany; \\ johannes.preussner@iwm.fraunhofer.de \\ * Correspondence: carlos.jimenezpena@kuleuven.be; Tel.: +32-9265-86-10
}

Received: 11 February 2020; Accepted: 25 February 2020; Published: 28 February 2020

\begin{abstract}
High-strength low-alloy steels (HSLA) are gaining popularity in structural applications in which weight reduction is of interest, such as heavy duty machinery, bridges, and offshore structures. Since the fatigue behavior of welds appears to be almost independent of the base material and displays little improvement when more resistant steel grades are employed, the use of bolted joints is an alternative joining technique which can lead to an increased fatigue performance of HSLA connections. Manufacturing a hole to allocate the fastener elements is an unavoidable step in bolted elements and it might induce defects and tensile residual stresses that could affect its fatigue behavior. This paper studies and compares several mechanical (punching, drilling, and waterjet-cut) and thermal (plasma and laser-cut) hole-making procedures in HSLA structural plates. A series of 63 uniaxial fatigue tests was completed, covering three HSLA grades produced by thermomechanically controlled process (TMCP) with yield strength ranging from 500 to $960 \mathrm{MPa}$. Samples were tested at single load level, which was considered representative in HSLA typical applications, according to the input received from end users. The manufactured holes were examined by means of optical and electron microscopy, 3D point measurement, micro hardness tests, $\mathrm{X}$-ray diffraction, and electron backscatter diffraction (EBSD). The results give insight on cutting processes in HSLA and indicate how the fatigue failure is dominated by macro defects rather than by the steel grade. It was shown that the higher yield strength of the HSLA grades did not lead to a higher fatigue life. Best fatigue results were achieved with laser-cut specimens while punched samples withstood the lowest amount of cycles.
\end{abstract}

Keywords: high-strength low-alloy; hole manufacturing; fatigue; drilling; punching; waterjet-cutting; plasma-cutting; laser-cutting

\section{Introduction}

The field of application for high-strength low-alloy (HSLA) steels ranges from heavy duty equipment to offshore and civil engineering applications [1-6]. The greater yield strength of higher strength structural steels allows slender structural designs and lower self-weight loads, which result in economic and environmental benefits. However, structural steel grades with extremely high yield strength (up to $1100 \mathrm{MPa}$ ) are generally associated with a large concentration of alloying elements and 
they are traditionally produced by quenching and tempering (QT) [7]. These HSLA grades have a high hardenability, which may lead to potential brittle fracture and, when used in welds, hydrogen-induced fracture [8]. Alternatively, HSLA grades produced by thermomechanically controlled process (TMCP) are considered a good compromise between mechanical properties and fatigue resistance. TMCP allows us to produce a wide range of HSLA grades with diverse microstructures and material properties which are often adopted in civil and mechanical structures. The applied rolling scheme is individually designed depending on the chemical composition, the thickness, and further parameters, which result in multiple TMCP HSLA microstructures types [9]. The leaner steel composition results in improved weldability compared to QT HSLA grades. The fatigue performance of welded HSLA, however, seems to be practically independent from the base material and it displays little improvement when more resistant steel grades are employed compared with milder steel grades [10]. In order to tackle this issue, special post-weld treatments are to be carried out [11].

The use of bolted joints over welded joints in HSLA structures is contemplated as an option to avoid the problems associated with welding. While microstructural changes or temperature-induced stresses are not an issue in bolted connections, specific parameters such as the bolt preload [12] or the hole-making process [13] play a critical role in the fatigue performance of HSLA structures and might influence additional failure modes such as fretting wear or fatigue associated with the relative displacement between bolted plates. Additional damaging phenomena such as wear or fretting fatigue due to the small relative displacement between two bolted elements might pose. An essential requirement in bolted connections is the presence of a hole to allocate the fastener elements and, therefore, the necessity of a cutting process to produce this hole. Cutting procedures are part of almost every steel product manufacturing process, with numerous cutting techniques being available, depending on application requirements such as the cut tolerance, edge quality, economical aspects, and so on. The cut-edges often form an integral part of the structure and sustain high stresses. In applications under cyclic loading, and due to the fact that fatigue is strongly influenced by the surface, the characteristics of the cut-edge play a crucial role in the life of the mechanical component. Mechanical cutting processes can induce cold-work hardening into the material [14] or surface defects due to cracking or material removal [13] while thermal cutting processes also induce a heat-affected zone (HAZ) surrounding the cut-edge [15]. The study of the quality and performance of HSLA as-cut edges has gained increased interest in recent industrial research. Two European-funded researches have studied the fatigue performance of thermally and mechanically cut edges in moderately thick steels with yield strength ranging from 355 to $890 \mathrm{MPa}$. In the Coldfossproject [16], the fatigue performance and hole quality of punched and drilled holes was investigated. It was reported that although mechanical cutting processes could lead to reduction of performance in some cases, this was not a concern in most conventional design situations. In the Hipercut project [17], the influence of laser beam and plasma-arc cutting processes on the edge quality and the process parameters was optimized for best in-service performance. The edge quality was found to be strongly dependent on the microstructure and the thickness of the material, and the process parameters had to be modified accordingly. A previous research by the authors [13] covered the effect of the most common hole-making processes (thermal and mechanical) on the fatigue behavior on the HSLA grade S500MC. The results revealed how different thermal and mechanical cutting processes affected the material, the fatigue performance, and the geometrical accuracy of the tested samples. For instance, drilling was found to produce the most geometrically accurate hole and the smoothest surface finish, while laser and waterjet cutting displayed the best fatigue performance. It was found that aspects like the hole morphology and geometrical distortions were found not to affect the fatigue performance as much as the presence of large individual defects. However, it was not clear how other HSLA grades, with increased resistance and decreased ductility, might behave.

Hole-making procedures are covered by many constructional standards. However, several standards refer only to holes made by punching or drilling $[18,19]$ or include local hardness restrictions that can be excessively limiting for thermal cutting processes $[18,20]$. These constraints, together 
with the restrictions imposed already on HSLA with a yield strength exceeding $700 \mathrm{MPa}$ [21], might limit even further the use of HSLA in structural applications. Additional research on hole-making procedures in HSLA grades and their performance under cyclic loading might extend the use of HSLA to further structural applications and reduce manufacturing costs.

This research aimed to extend previous knowledge on the HSLA grade S500MC [13] to higher strength grades, S700MC and S960MC, which are characterized by a delicate multiphase microstructure, containing a significant fraction of metastable phases, like martensite and bainite. These phases typically exhibit high strength, but they can also be brittle under high-strain rates. Thus, the presence of these phases is expected to affect the response of the material during the mechanical hole-making processes. Furthermore, the grades S700MC and S960MC contain an increased concentration of alloying elements for achieving the required hardenability. The complex microstructure of S700MC and S960MC, being metastable, is prone to softening or transformation under the influence of heat. A series of fatigue tests were performed to S700MC and S960MC samples with holes produced by the most commonly used mechanical and thermal hole-making procedures. The nature of the manufactured holes will be evaluated by means of optical and electron microscopy, topographic measurements, and hardness tests. Additional electron backscatter diffraction (EBSD) and residual stress measurements were performed on the S500MC and S960MC grades. The fatigue behavior and hole morphology of these steel grades will be compared with those obtained by the authors on the HSLA grade S500MC [13].

\section{Materials and Methods}

\subsection{Material}

Two widely used commercial TMCP HSLA grades were considered in this investigation, S700MC and S960MC, supplied in rolled plates of $1500 \mathrm{~mm} \times 1000 \mathrm{~mm} \times 5 \mathrm{~mm}$. The steel grades are thermomechanically rolled $(\mathrm{M})$ structural steels $(\mathrm{S})$ with a specified minimum yield strength at ambient temperature of 700 and $960 \mathrm{MPa}$, respectively. These HSLA grades were compared with the HSLA grade S500MC which was evaluated in [13]. Digital image correlation was applied to extract the averaged strain field in the central region of dog-bone samples tested under uniaxial loading. The employed procedure is partly described in [22]. The chemical composition of the steels was provided by the manufacturers $[23,24]$ and it is summarized in Table 1 together with the measured mechanical properties.

Table 1. Chemical composition and mechanical properties of HSLA grades.

\begin{tabular}{|c|c|c|c|c|c|c|c|c|c|c|c|}
\hline \multicolumn{12}{|c|}{ Chemical Composition (wt.\%) } \\
\hline Grade & $\mathrm{C}$ & $\mathrm{Si}$ & Mn & $\mathbf{P}$ & $S$ & Al & $\mathrm{Nb}$ & $\mathbf{V}$ & $\mathrm{Ti}$ & Mo & B \\
\hline S500MC & $\leq 0.120$ & $\leq 0.500$ & $\leq 1.700$ & $\leq 0.025$ & $\leq 0.015$ & 0.015 & $\leq 0.090$ & $\leq 0.200$ & $\leq 0.150$ & - & - \\
\hline S700MC & $\leq 0.120$ & $\leq 0.600$ & $\leq 2.100$ & $\leq 0.025$ & $\leq 0.015$ & $\geq 0.015$ & $\leq 0.090$ & $\leq 0.200$ & $\leq 0.220$ & $\leq 0.5$ & $\leq 0.0050$ \\
\hline S960MC & $\leq 0.120$ & $\leq 0.250$ & $\leq 1.300$ & $\leq 0.020$ & $\leq 0.010$ & $\geq 0.015$ & $\leq 0.050$ & $\leq 0.050$ & $\leq 0.070$ & - & - \\
\hline \multicolumn{12}{|c|}{ Mechanical properties } \\
\hline Grade & \multicolumn{2}{|c|}{$\begin{array}{l}\text { Young } \\
\text { modulus } \\
(\mathrm{GPa})\end{array}$} & \multicolumn{3}{|c|}{ Yield stress (MPa) } & UTS (MPa) & \multicolumn{3}{|c|}{ Elongation (\%) } & \multicolumn{2}{|c|}{$\begin{array}{l}\text { Hardness } \\
\text { (HV0.2) }\end{array}$} \\
\hline S500MC & \multicolumn{2}{|c|}{210} & \multicolumn{2}{|c|}{$562 \pm 6$} & \multicolumn{2}{|r|}{$658 \pm 4$} & \multicolumn{3}{|c|}{$13.7 \pm 1.2$} & \multicolumn{2}{|c|}{$207 \pm 7$} \\
\hline S700MC & \multicolumn{2}{|l|}{210} & \multicolumn{2}{|c|}{$731 \pm 3$} & \multicolumn{2}{|r|}{$801 \pm 4$} & \multicolumn{3}{|c|}{$11.8 \pm 0.6$} & \multicolumn{2}{|c|}{$266 \pm 9$} \\
\hline S960MC & \multicolumn{2}{|l|}{210} & \multicolumn{2}{|c|}{$977 \pm 7$} & \multicolumn{2}{|r|}{$1061 \pm 8$} & \multicolumn{3}{|c|}{$3.2 \pm 0.2$} & \multicolumn{2}{|c|}{$344 \pm 6$} \\
\hline
\end{tabular}

\subsection{Sample Design}

The sample design, shown in Figure 1, is similar to the sample design previously employed by the authors in [13]. The sample consists of a dog-bone shaped tensile specimen without fastener elements in order to isolate the effect of the hole-making process from the other parameters governing bolted 
connections, such as the bolt preload and the washer geometry. The distance from the hole edges was 1.5 times the hole diameter, as specified in the Eurocode standard EC3-1-8 for bolted connections under cyclic loading [25]. The hole diameter produced by every hole-making process was $18 \mathrm{~mm}$, a value which is currently used by industrial partners in their bolted joint applications.

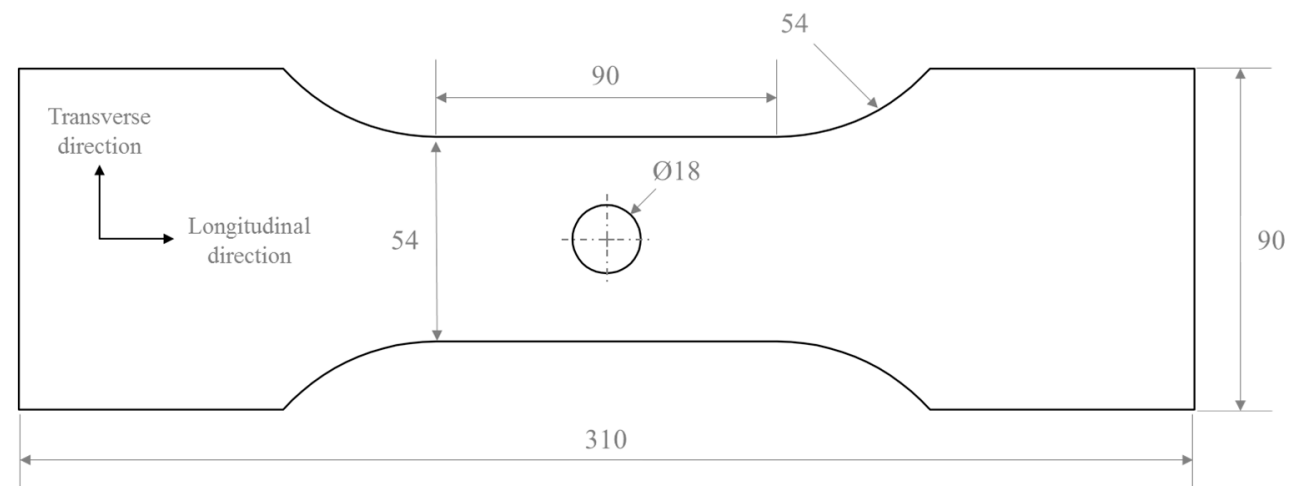

Figure 1. Sample design. Units are specified in $\mathrm{mm}$.

\subsection{Microstructural Characterization}

Light optical microscopy images were taken with a VHX 5000 Keyence digital microscope (Keyence Corporation, Osaka, Japan) equipped with image analysis software. The characterization with scanning electron microscopy (SEM) was performed using a JEOL JSM-6500F (JEOL USA, Inc., Peabody, MA, USA) operated at $15 \mathrm{kV}$. A standard metallographic preparation procedure was followed and etching was performed with Nital 2\% (98\% Ethanol and 2\% HNO3). The fracture surfaces were immersed with acetone in an ultrasonic bath to remove artifacts. The microstructure was further observed with a field emission gun scanning electron microscope (SEM) Zeiss Supra 40VP (Carl Zeiss SMT GmbH, Oberkochen, Germany) with $20 \mathrm{kV}$ accelerating voltage and a secondary electron (SE) detector or the electron backscatter diffraction (EBSD) technique. For the acquisition of EBSD patterns, an aperture of $30 \mu \mathrm{m}$ was used. The working distance needed to be adapted at each scan according to the sample size and the region of interest. The samples were tilted by $70^{\circ}$ towards the EBSD detector, a DigiView 3 camera (AMETEK GmbH, Weiterstadt, Germany), which was operated with the EDAX-TSL-OIM-Data Collection software (EDAX Inc., MahWah, NJ, USA) version 6, was used.

\subsection{Hole-Making Procedures}

The hole-making procedures employed in this investigation corresponded with the methods employed in the S500MC study [13]: Punching (three conditions), drilling, waterjet cutting, laser cutting, and plasma cutting. Two punch geometries were investigated: A flat punch and a chamfered punch (shown in Figure 2). The orientation of the chamfered punch with respect to the axial loading was also investigated. The geometry of the punch is shown in Figure 2. Some of the hole-making techniques were modified from [13] to adapt to the new material properties and thickness. The optimal process parameters were provided by the industrial partners and are included in Table 2. All cutting processes were evaluated for all three HSLA steel grades.

Punching was executed with an EDEL Stanzomat 407-20 punching press (Edel stanztec gmbh \& Co.K, Bietigheim-Bissingen, Germany). Drilling was performed in a Kunzmann WF 7/3-320 CNC machine (Robert Kunzmann GmbH \& Co. KG, Tullastraße, Germany) for improved accuracy. The drilling process parameters were given by the drill manufacturer. The drill bit type used was a VDS201F18000 VariDrill (Kennametal Widia Produktions GmbH \& Co. KG, Essen, Germany) solid carbide drill [26]. Waterjet-cut holes were produced with an OMAX 55100 Jet Machining Center (Omax Corporation, Kent, WA, USA). Laser cutting was performed with a Trumpf TruLaser 3040 laser cutting machine (Trumpf GmbH + Co. KG, Ditzingen, Germany). Plasma-cut samples were produced with a 
ESAB Combirex DX 3500 plasma cutting machine (Elektriska Svetsnings-Aktiebolaget, Gothenburg, Sweden).

(a)

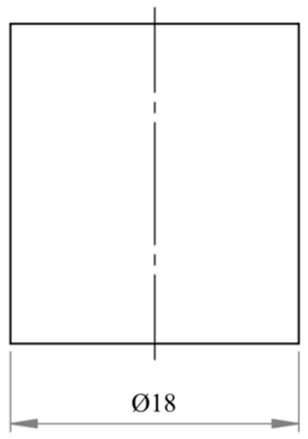

(b)

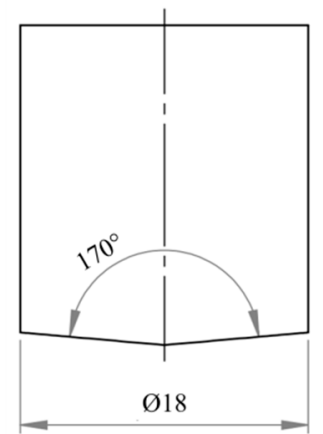

Figure 2. (a) Flat punch and (b) chamfered punch end geometry (Unit: mm).

Table 2. Cutting process parameters for S700MC and S960MC samples.

\begin{tabular}{|c|c|c|c|}
\hline \multicolumn{4}{|c|}{ Punching } \\
\hline Max. punching speed & & $20 \mathrm{~m} / \mathrm{min}$ & \\
\hline Cutting clearance & & $0.8 \mathrm{~mm}$ & \\
\hline Punch type & Flat & Chamfered & Chamfered \\
\hline Alignment & - & $0^{\circ}$ & $90^{\circ}$ \\
\hline \multicolumn{4}{|c|}{ Drilling } \\
\hline Cutting speed & & $80 \mathrm{~m} / \mathrm{min}$ & \\
\hline Feed & & $0.3 \mathrm{~mm} / \mathrm{rev}$ & \\
\hline Coolant & & Flood & \\
\hline Material Removal rate & & $108.02 \mathrm{~cm}^{3} / \mathrm{min}$ & \\
\hline Torque at tool & & $31.92 \mathrm{Nm}$ & \\
\hline \multicolumn{4}{|c|}{ Waterjet } \\
\hline Normal offset & & $1.27 \mathrm{~mm}$ & \\
\hline Radial offset & & $0.32 \mathrm{~mm}$ & \\
\hline High pressure setting & & $379.2 \mathrm{MPa}(55,000 \mathrm{psi})$ & \\
\hline Low Pressure setting & & 137.9 $\mathrm{MPa}(20,000 \mathrm{psi})$ & \\
\hline Mixing tube diameter & & $0.762 \mathrm{~mm}$ & \\
\hline Jewel diameter & & $0.3048 \mathrm{~mm}$ & \\
\hline Abrasive flow rate & & $0.3073 \mathrm{Kg} / \mathrm{min}$ & \\
\hline \multicolumn{4}{|c|}{ Laser } \\
\hline Beam power & & $4000 \mathrm{~W}$ & \\
\hline Cutting speed & & $6.5 \mathrm{~m} / \mathrm{min}$ & \\
\hline Nozzle diameter & & $0.8 \mathrm{~mm}$ & \\
\hline Nozzle distance & & $0.7 \mathrm{~mm}$ & \\
\hline Focus diameter & & $-1.8 \mathrm{~mm}$ & \\
\hline \multicolumn{4}{|c|}{ Plasma } \\
\hline Current & & $100 \mathrm{~A}$ & \\
\hline Nozzle & & $4.1 / 1.4(\mathrm{~mm})$ & \\
\hline Speed & & $2159 \mathrm{~mm} / \mathrm{min}$ & \\
\hline Torche standoff & & $4 \mathrm{~mm}$ & \\
\hline Height control & & Not Active & \\
\hline
\end{tabular}

\subsection{Hole Geometry Evaluation}

The overall shape of the hole was investigated by probing the hole surface at different depths with a coordinate measurement apparatus. A Mitutoyo BX303 Manual Coordinate Measuring Machine 
(Mitutoyo Corporation, Kawasaki, Kanagawa, Japan) was used to measure the diameter of the hole along the thickness of the sample. The 12 point measurements were obtained at every millimeter of the hole depth. The hole diameter with respect to the hole depth was then calculated using a Gaussian fit.

\subsection{Surface Profiling}

Surface profiles of the different hole surfaces were obtained by means of laser scanning microscopy. The large measured area, compared to other tactile measurements techniques, provides a general overview of the topography of each hole type. A Keyence VK-9700 Laser Confocal microscope (Keyence Corporation, Osaka, Japan) was used to perform the measurements. A section of $2.5 \mathrm{~mm}$ by $0.5 \mathrm{~mm}$ was examined per hole, with an average amount of 2.5 million data points. The point clouds were filtered to eliminate outliers and measurement errors.

\subsection{Micro Hardness Mapping}

Hardness measurements were performed alongside the hole cross-section in order to evaluate the hardening induced by each hole-making process, either due to cold-work hardening or due to microstructural changes. The measurements covered a region of $5 \mathrm{~mm}$ by $5 \mathrm{~mm}$ (thickness of the hole) and they were distributed in steps of $500 \mu \mathrm{m}$ for both directions. The spacing between micro-indentations complied with the Vickers hardness test standard for metallic materials (ISO 6507-1: 2005) [27]. The hardness measurements were performed with a Struers DuraScan G5 automated hardness tester (Struers ApS, Ballerup, Denmark).

\subsection{Residual Stresses}

Previous research by the authors [13] indicated the absence of hardening in the waterjet-cut and drilled samples. The abrasive cutting nature of these processes results in a very localized surface damage next to the produced hole. This was not the case for punching or laser-cut, where considerable hardening was measured near the hole. Since hardness measurements can be also affected by the presence of residual stresses induced during the hole-making process, a more detailed evaluation of the residual stress analysis was conducted with X-ray diffraction (XRD). By measuring the strain in the crystal lattice and assuming a linear elastic distortion, the residual stresses producing that distortion was calculated [28]. The residual stress analysis was conducted at laser cut and punched specimens at the S500MC and S960MC grades. To account for stress gradients, the residual stresses on the surface of the four samples were measured in a straight line perpendicular to the hole rim with increasing distance to the hole $(1.0 \mathrm{~mm}, 2.0 \mathrm{~mm}, 3.0 \mathrm{~mm}, 4.0 \mathrm{~mm}, 5.0 \mathrm{~mm})$. Because the punched samples had deformed zones directly at the hole rim, the center of the first measurement point was at $1.0 \mathrm{~mm}$ distance to the hole rims to achieve an equivalent measurement for both production processes. To account for singularities and to investigate the reproducibility in the measurements, both sides of the holes (left and right side to the hole) were measured. Both sides of the plates (top and bottom side) were measured to see influences from the entry and exit of the punching/laser cutting process. On some samples a few microns of the surface layer had to be removed using chemical etching to remove oxides and impurities that might affect the results. Measurements were performed on a Stresstech X3000-G3 XRD diffractometer (Stresstech GmbH, Rennerod, Germany) and in both the longitudinal and transverse direction (Figure 1). The residual stresses were determined with respect to the 211 peak of $\alpha$-Fe $\left(2 \theta_{0}=156.4^{\circ}\right)$ using $\mathrm{Cr}$-K $\alpha$-radiation. The measurement was determined by the $\sin ^{2} \psi$ method, collecting $15 \psi$-angles that were equally distributed over a tilt between $-45^{\circ}$ and $+45^{\circ}$. The diameter of the X-ray spot was $1 \mathrm{~mm}$ at incident beam with an estimated penetration depth of $12 \mu \mathrm{m}$. The residual stresses were calculated using a Young's modulus of 211,000 MPa, a Poisson's ration of 0.3, and an absorption coefficient of $89.7 \mathrm{~mm}^{-1}$. 


\subsection{Fatigue Testing}

Fatigue tests were performed with a Zwick HA100 servo-hydraulic load frame (Zwick Roell Group, Ulm, Germany) with a maximal axial load of $100 \mathrm{kN}$. As in [13], the test stress ratio was set to $R=0.1$ and the test frequency to $f=25 \mathrm{~Hz}$. The stress range was selected after an initial experimental study with the objective of achieving an average number of 1 million cycles between all holing conditions and both grades, which was considered representative in typical heavy duty applications. This decision was motivated by the requirements of the industrial end users involved in the present research project. The loading level employed in [13] was insufficient to provoke fracture under 5 million cycles due to the lower fatigue resistance of the base material with respect to the more resistant HSLA grades. The chosen applied nominal stress range was $300 \mathrm{MPa}$. The run-out number of cycles was set to $5 \times 10^{6}$ fatigue cycles. Three repetitions were performed for each test condition, resulting in a total test number of 42 fatigue tests. In addition, the 21 fatigue samples made of S500MC and tested in [13] by the authors were also more extensively evaluated in this research, as previously mentioned in Sections 3.6 and 3.7, resulting in a total number of 63 specimens covering three HSLA yield strength ranging from 500 to $960 \mathrm{MPa}$.

\section{Results and Discussion}

\subsection{Microstructural Characterization}

The microstructure of the S700MC is shown in Figure 3a and it was formed by ferrite and bainite, together with carbides. The microstructure of the S960MC on the other hand (Figure 3b) was composed of a martensitic matrix, cementite, or $\mathrm{M}_{7} \mathrm{C}_{3}$ carbides and retained austenite.

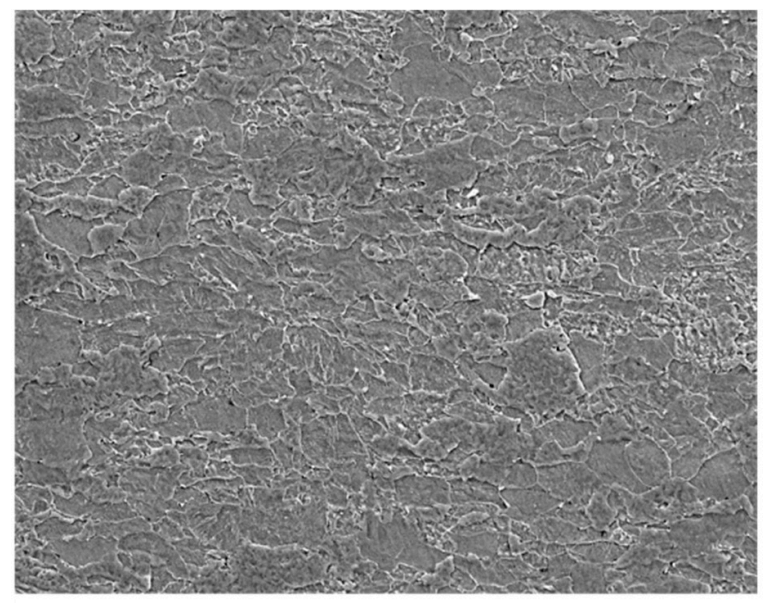

(a) $\mathrm{S} 700 \mathrm{MC}$

$\mathrm{x} 2000$

$10 \mu \mathrm{m}$

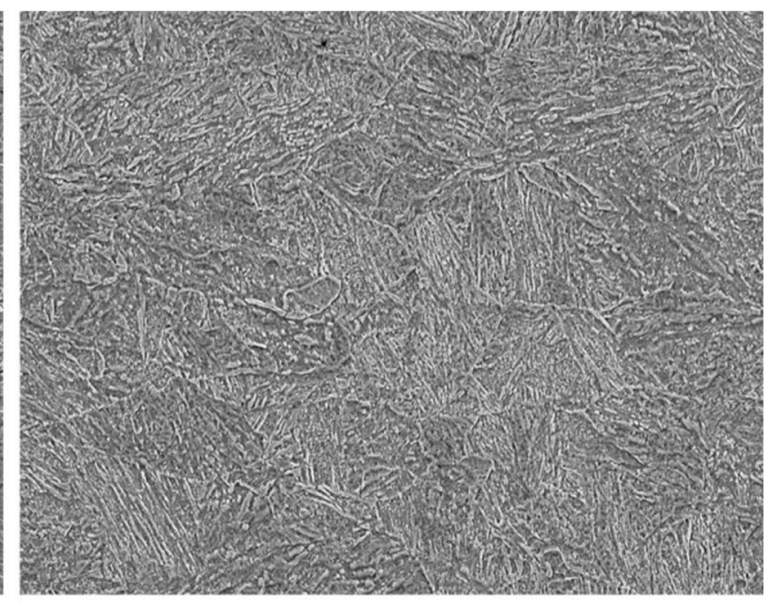

(b) S960MC

$\mathrm{x} 2000$

$10 \mu \mathrm{m}$

Figure 3. Microstructure micrograph for (a) 700MC and (b) S960MC.

The microstructures evaluated in this research differed significantly from the ferritic microstructure of the HSLA grade S500MC studied in [13]. The harder and finer martensitic phases of the S700MC and S960MC microstructure, together with the resulting lower formability, affected the hole quality and the fatigue properties of the cut edges.

\subsection{Hole Surface Evaluation}

The optical analysis of the hole surfaces revealed significant differences between hole-making conditions. In Figure 4, the surface of the punched holes (flat punch) is shown. The shear-cutting section was formed by dimples elongated in the direction of the punch travel. A large amount of shear dimples was observed in the S700MC and S960MC steel grades, in which large sections of the hole surface were removed during punching. This phenomenon is displayed in Figure 4a for the S700MC 
and it was observed in all punching conditions. The dimples were much less present in the S500MC punched samples [13], where most of the surface was covered by smooth and highly deformed material. During the initial penetration of the punch in hole making process, the S500 formed coarse dimples when the hole began to form. However, the dimples were smeared away during the penetration of the punch. On the cutting surface of S700MC, Figure 4b, and S960MC, Figure 4c, more dimples could be observed. This is because the microstructure in these grades was mostly of martensitic nature, therefore more difficult to smear away due to the increased hardness. The dimples in these cases were smaller, because the original microstructure was finer and contained carbides, which act as nucleation sites for the dimples. This fact makes the dimples more uniformly distributed in the higher strength grades than in the S500MC.

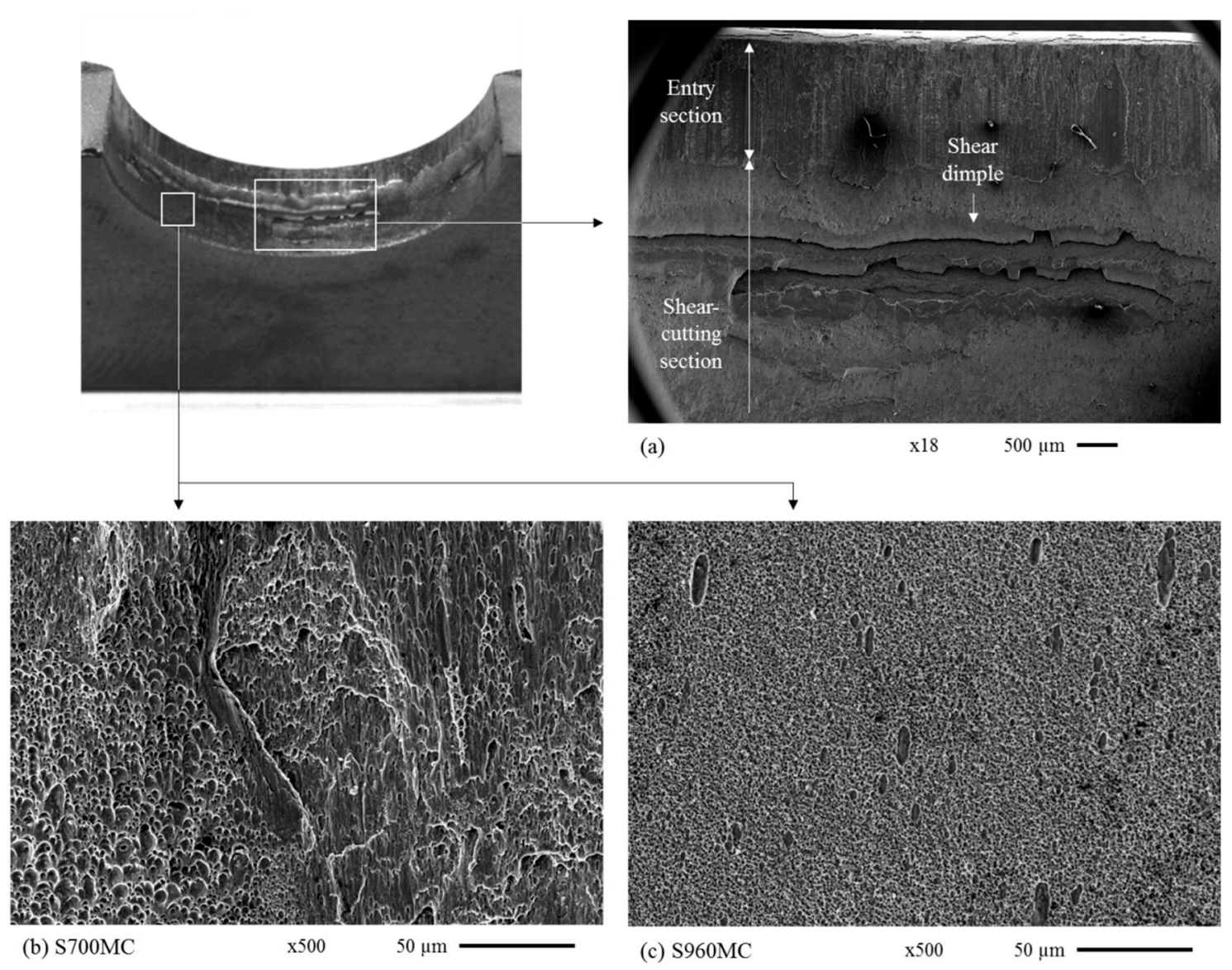

Figure 4. (a) SEM overview of entry and shear-cutting sections in punched holes. Below, a detailed view of the exit side is shown, where differences between (b) S700MC and (c) S960MC are evident.

The remaining hole-making techniques produced hole surfaces with similar features, independently of the steel grade. Drilling always resulted in a smooth, feature-less surface, with no visible characteristics apart from the drill-traces in the direction of the drill rotation, noted in Figure 5a. Drilling also produced a characteristic drill-chip, which is normally removed manually with a deburring tool. The chip was left intact, as in the previous research by the authors [13]. Waterjet-cutting produced highly abraded surfaces, with multiple dents at the locations in which the material was removed by the abrasive jet. A characteristic waterjet-cut surface is shown in Figure 5b. Both laser-cut (Figure 5c) and plasma-cut (Figure 5d) surfaces were covered by a regular crack pattern. Cracks were very superficial and likely to be formed on a thin surface layer covering the hole surface. Plasma-cut surfaces additionally displayed traces in the direction of the hole, which indicate that the material at that location was extensively melted and resolidified. The location in which the plasma first entered the material was also characterized by the presence of a large blob of solidified material. In order to 
avoid any effect caused by this distinct surface condition, the plasma-cutting process was adjusted so the entry point of the plasma jet was not located at the expected fracture location (midsection of the hole) but at an angle of 45 degrees with respect of the axial loading. Similar observations for the drilled, waterjet-cut, laser-cut, and plasma-cut holes were made for the HSLA grade S500MC in [13], hinting at the independence of the hole surface from the microstructure of the steel. In drilling and waterjet cutting, the surface was highly abraded and no distinct features were distinguishable between steel grades. In thermal cutting processes the surfaces were melt and resolidified into a new martensitic microstructure, which was also similar in all grades.

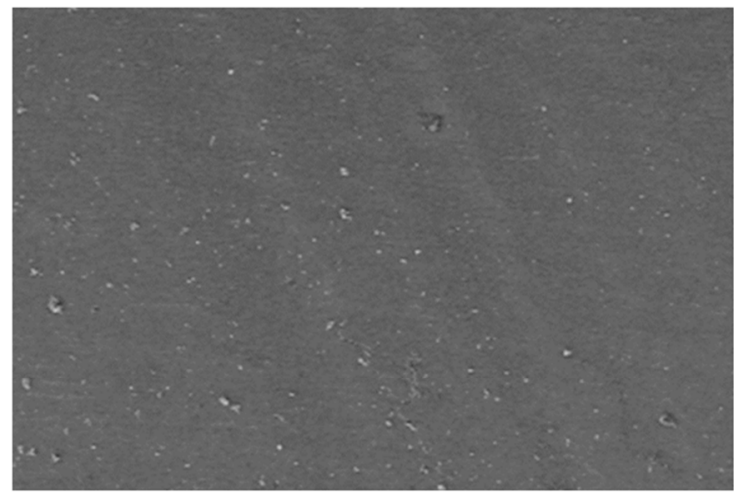

(a)

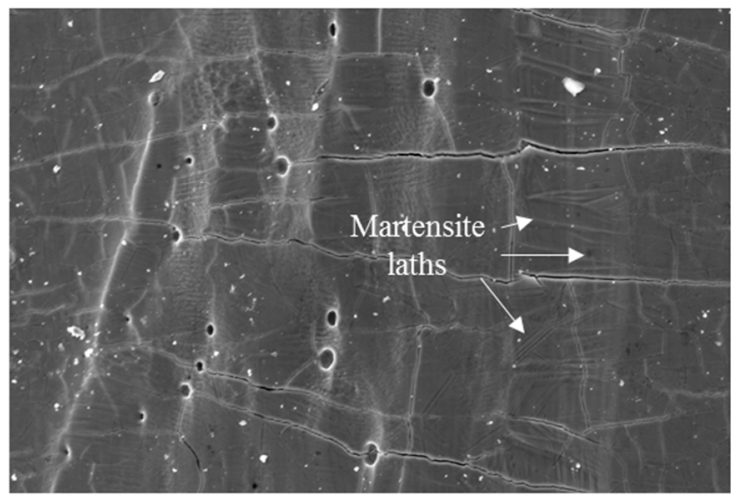

(c)

$$
\mathrm{x} 500
$$$$
50 \mu \mathrm{m}
$$

$100 \mu \mathrm{m}$

Figure 5. Hole surfaces produced by (a) drilling, plasma cutting.

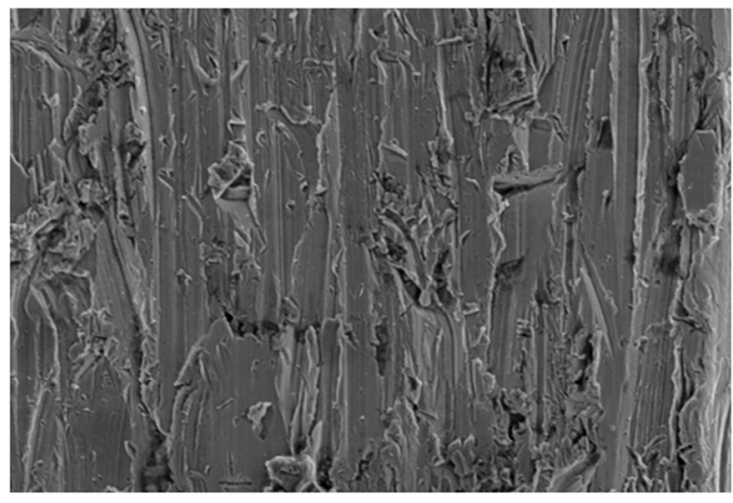

(b)

$\mathrm{x} 500$

$50 \mu \mathrm{m}$

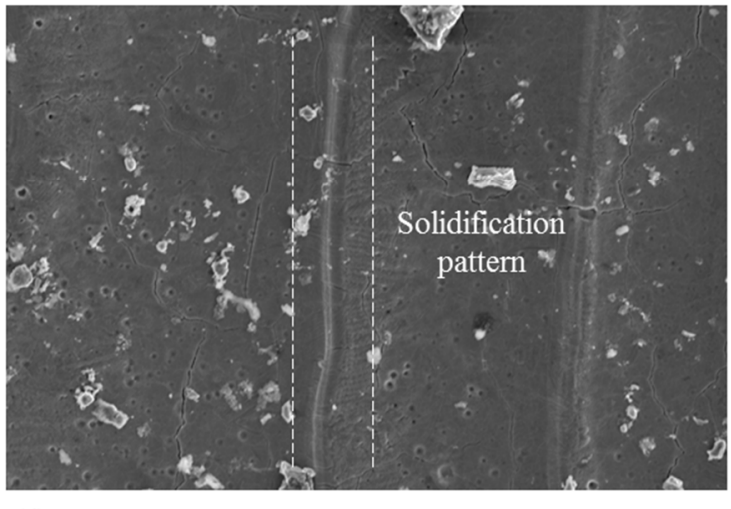

(d)

$\mathrm{x} 500$

$50 \mu \mathrm{m}$

(b) waterjet cutting, (c) laser cutting, and (d)

Similarly to [13], protruding acicular structures were observed in the laser cut of all HSLA grades, indicating the presence of martensite formation. These structures were also found in the plasma-cut surfaces but not as clearly and in the quantity observed in the laser-cut samples. The cross-section of the thermally cut specimens was further studied to evaluate the layer of transformed material. Cross-sections of the laser- (above) and plasma- (below) cut holes are displayed in Figure 6. The analysis of the heat-affected zone (HAZ) revealed that there is a microstructurally affected layer surrounding the hole. This layer was characterized by martensitic microstructure. The dominant presence of martensite was a result of the large heat input from the cutting process and the subsequent fast cooling. The extension of the HAZ in the plasma-cut specimens was approximately three times larger than in the laser-cut specimens, in similarity with the S500MC grade [13]. 


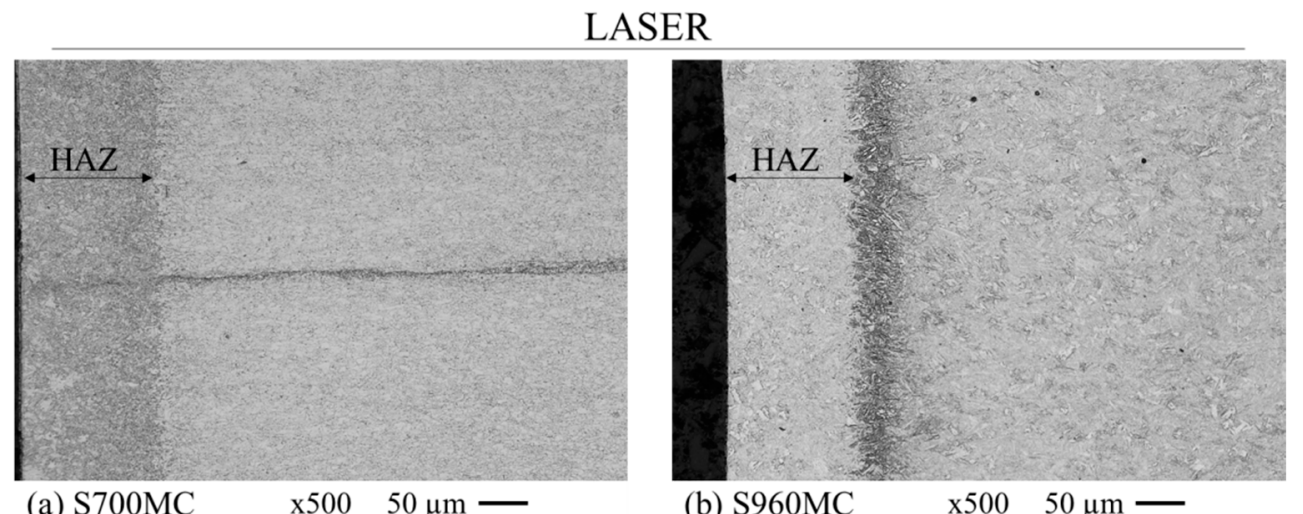

(a) S700MC

$\times 500 \quad 50 \mu \mathrm{m}-$

(b) S960MC

$\times 500 \quad 50 \mu \mathrm{m}-$

PLASMA

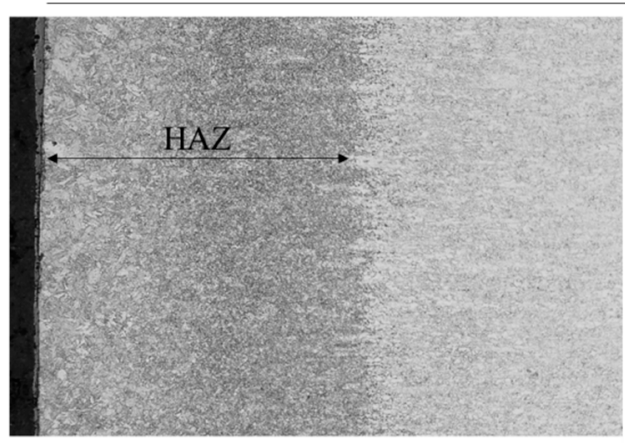

(c) $\mathrm{S} 700 \mathrm{MC}$

$\times 500 \quad 50 \mu \mathrm{m}$

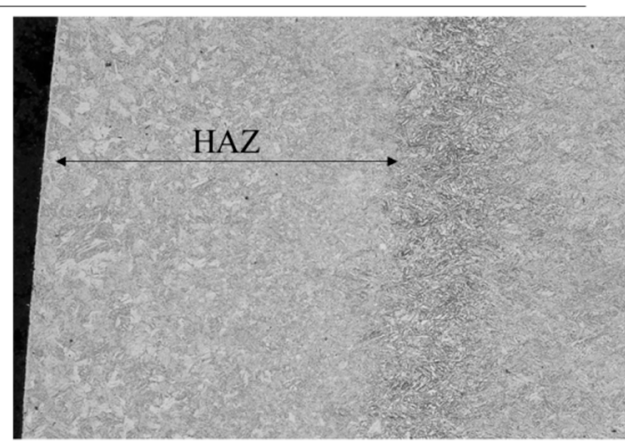

(d) $\mathrm{S} 960 \mathrm{MC}$

$\mathrm{x} 500 \quad 50 \mu \mathrm{m}-$

Figure 6. Cross-section of thermal-cut holes: $(\mathbf{a}, \mathbf{b})$ Laser and $(\mathbf{c}, \mathbf{d})$ plasma.

The average width of the HAZ was measured and it is displayed for all three HSLA grades in Figure 7. It can be noted that the difference between plasma- and laser-cut HAZ widths was bigger for S700MC and the S960MC and that the HAZ in both thermal processes tended to be wider with increasing material strength.

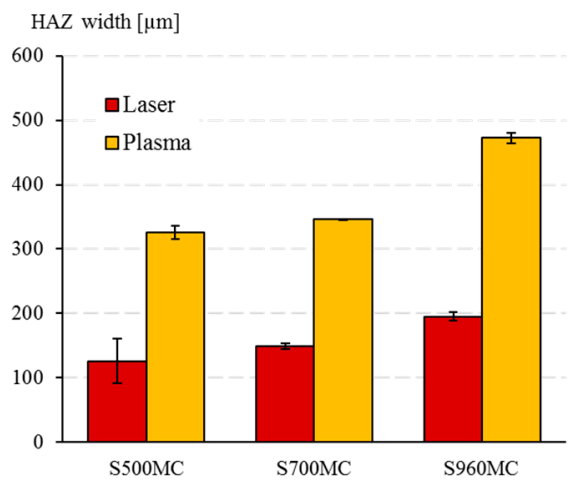

Figure 7. Average HAZ width in laser- and plasma-cut holes for S500MC, S700MC, and S960MC.

Additionally, the cross-sectional analysis revealed the presence of centerline segregation indicated in Figure $6 \mathrm{a}$, in the all three HSLA grades. This is related to the continuous casting production process. The centerline segregation can lead to local embrittlement [29].

\subsection{Surface Topology Evaluation}

The surface profiles obtained by laser microscopy allowed to observe the predominant features that some of the hole-making techniques had in certain directions. A wavy pattern can be observed in laser-cut holes. This striation pattern is produced by the laser pulsations during the cutting process. 
This waviness was not observed in the plasma-cut surface, which appeared flat, but was also covered by striations or ridges. These ridges were observed to be long and straight in the S500MC sample, see Figure $8 \mathrm{~b}$, and short and interconnected in the S960MC sample. They related with the solidification patterns previously discussed in Section 3.2. The analysis of the punched samples indicated that roughness differed locally in sections with a large amount of removed material (shear dimples). A distinct step was found in the punched S960MC sample (Figure 8c), which indicated that the morphology of the hole is largely dependent on the presence of shear dimples. Finally, the waterjet-cut samples were found to have a granular surface topology caused by the abrasive cutting process, as shown in Figure 8d.
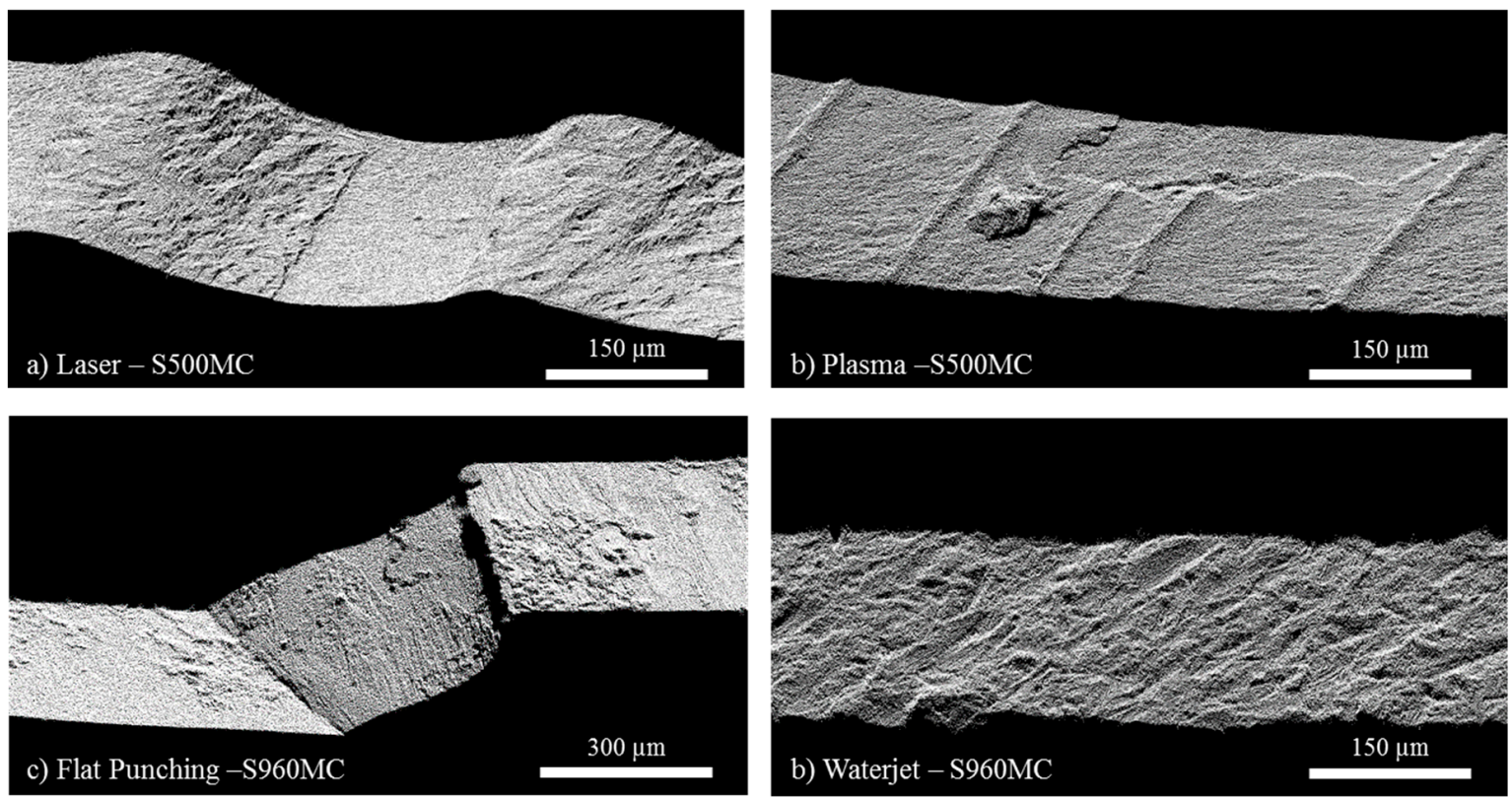

Figure 8. Surface profile of (a) laser-cut hole (S500MC), (b) plasma-cut hole (S500MC), (c) flat punching (S960MC), and (d) waterjet-cut hole.

\subsection{Hole Geometry Evaluation}

The averaged hole diameter for the S700MC and the S960MC steel grades is displayed in Figure 9. It is noted that the hole geometry was rather independent of the steel grade since both materials exhibited similar hole geometries for the same hole-making procedures. Drilling produced the most accurate hole geometry, with a constant hole diameter along the hole depth. Following, laser-cut resulted in a more deviated and undulating hole, with a less constant hole diameter. Waterjet-cutting displayed a tendency to produce an oversize hole diameter at the entry, which gradually shifted to a smaller hole diameter at the exit side of the hole. The waterjet-cut hole deviation did not exceed $0.2 \mathrm{~mm}$ in any case. Plasma-cut and punching resulted both in large deviations from the hole diameter. In the case of punched samples, an accurate hole diameter was produced at the hole start. However, at a depth of approximately $2 \mathrm{~mm}$, the hole started to widen due to the shear cutting of the material. The hole produced by plasma-cutting had the most distortions, with a large oversize at the entry and an undersized hole at the exit.

The variation of the obtained results between repetitions was generally low (below $0.1 \mathrm{~mm}$ for most cutting procedures) and it has not been included in the graph to improve its clarity. Punched S960MC samples, however, displayed a substantial maximum scatter $(0.203 \mathrm{~mm})$ which was approximately eight times larger than punched S700MC and S500MC [13] samples. The higher hardness of this steel might make the forming process more difficult and, hence, produce less constant results when using a punching process. The rest of cutting techniques produced geometrically similar holes in all grades. 


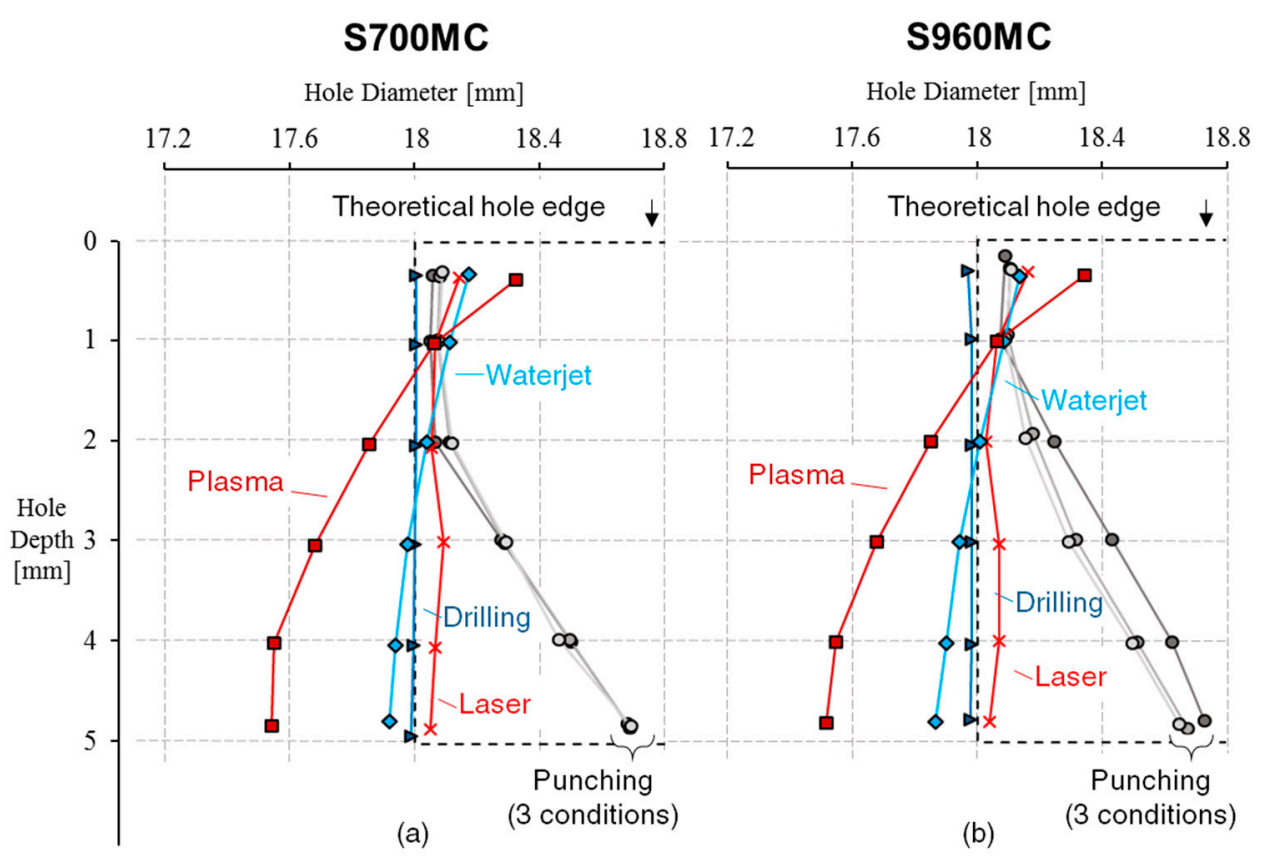

Figure 9. Hole diameter along sample thickness for waterjet cutting, laser cutting, drilling, and punching in (a) S700MC and (b) S960MC.

\subsection{Micro-Hardness Evaluation}

The produced hardening maps for the S700MC (Figure 10) and S960MC (Figure 11) show a clear increase in the material hardness near the edge for punching and the thermal cutting processes, similarly to the S500MC in [13].
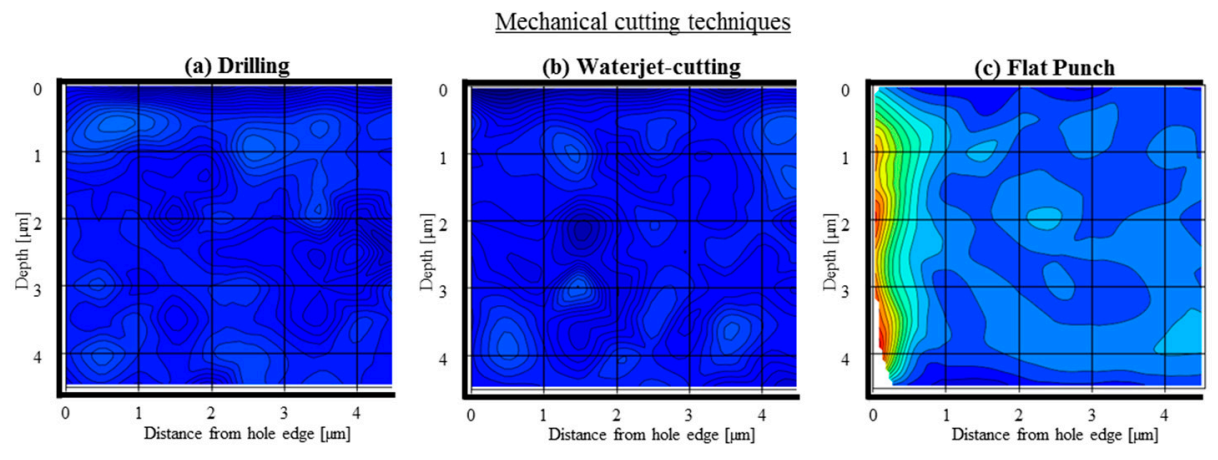

Thermal cutting techniques

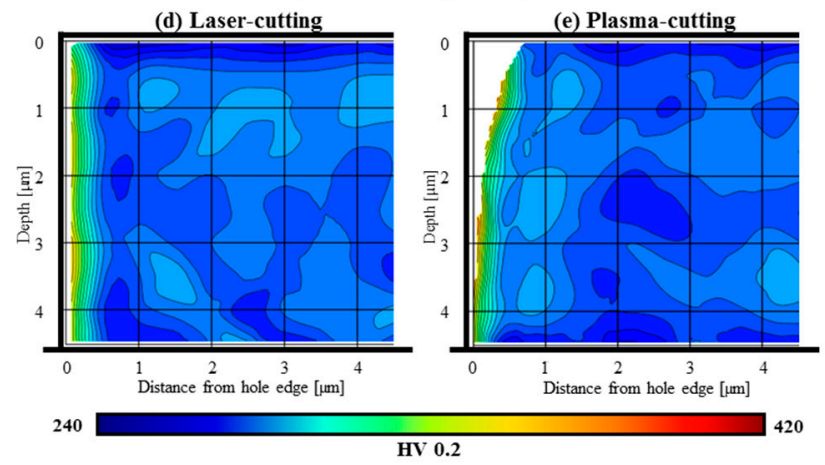

Figure 10. Hardness distribution near the hole edge in HSLA grade S700MC for various hole-making procedures: (a) drilling, (b) waterjet-cutting, (c) flat punching, (d) laser-cutting and (e) plasma-cutting. The hole edge is located on the left side of the images. 

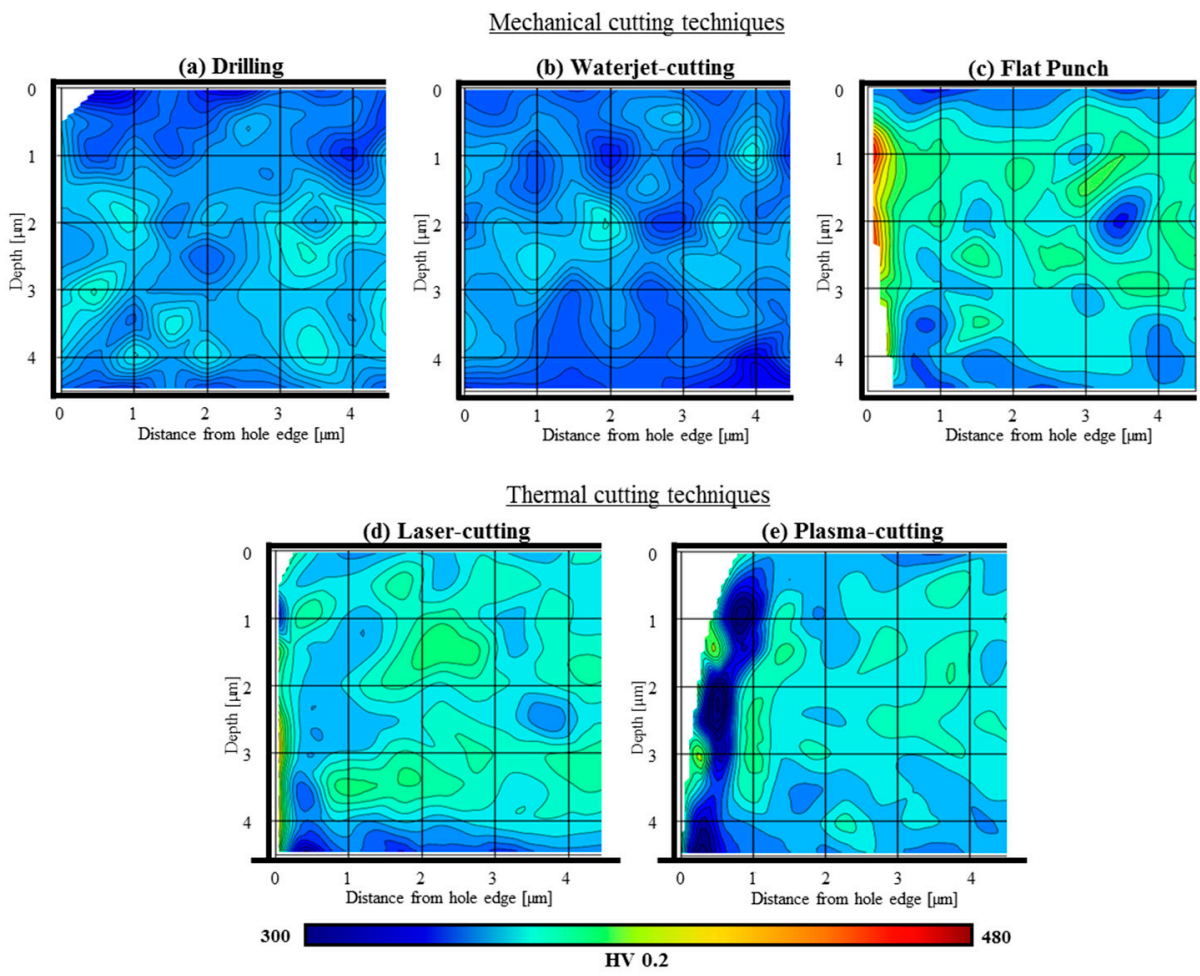

Figure 11. Hardness distribution near the hole edge in HSLA grade S960MC for various hole-making procedures: (a) drilling, (b) waterjet-cutting, (c) flat punching, (d) laser-cutting and (e) plasma-cutting. The hole edge is located on the left side of the images.

In the case of the punched samples, there was a clear hardness increase towards the hole edge. This phenomena has been already observed in punched specimens by Valtinat et al. [14] and can be attributed to the effect of cold-work hardening. The increase of hardness in punched samples (flat punch) with respect to the base material hardness was found to be $62 \%, 50 \%$, and $28 \%$ for the S500MC, S700MC, and S960MC HSLA grades, respectively. The hardness increase was in accordance with the differences in ductility of the HSLA grades. The punch shape and orientation also played a role in the final hardening distribution near the hole. As displayed in Figure 12, when the chamfered punch was employed and its sharp edges were not facing the measured surface $\left(0^{\circ}\right)$, the resulting hardening values were lower than when the other punching conditions were adopted. The chamfered punch at $90^{\circ}$ and the flat punch yielded, however, similar hardening distributions. This effect was mostly appreciable in the HSLA S960MC, while in the other two HSLA grades the punching conditions yielded similar results. This was related to the lower ductility and formability of the HSLA 960MC, which resulted in a less uniform strain accommodation along the entire hole.

A notable hardness increase was also found in the laser-cut samples, but mainly in the S700MC HSLA grade. The phase transformation triggered during the thermal cutting processes resulted in a thin layer of martensitic microstructure surrounding the hole edge. The hardness of this layer was significantly higher than the mixed bainitic-tempered martensitic of S700MC base material and similar to the martensitic matrix of the S960MC microstructure. The martensite formation could explain the notable hardness increase in the S700MC grades while in the S960MC grade this increase was barely significant. A similar hardening was found in the S700MC plasma-cut samples. However, the hardening effect for the S960MC grade differed from the rest of HSLA grades as regions of softer material were found just after the initial hardened HAZ layer. This is because the martensitic matrix of the S960MC was tempered extensively by the heat provided by the plasma. A more detailed hardness analysis was performed near the hole edge, with less distance between indentations, shown in Figure 13. It was observed that although there was a notable hardening increase at the hole edge, there was a decrease in hardness near the end of the HAZ layer. The measured Vickers hardness values at this 
region was $300 \mathrm{HV}$ 0.2, which represented an approximate decrease in hardness of $15 \%$ with respect to the base material hardness. The lower hardness of the layer adjacent to the plasma accounted for the softer regions observed in Figure 11.
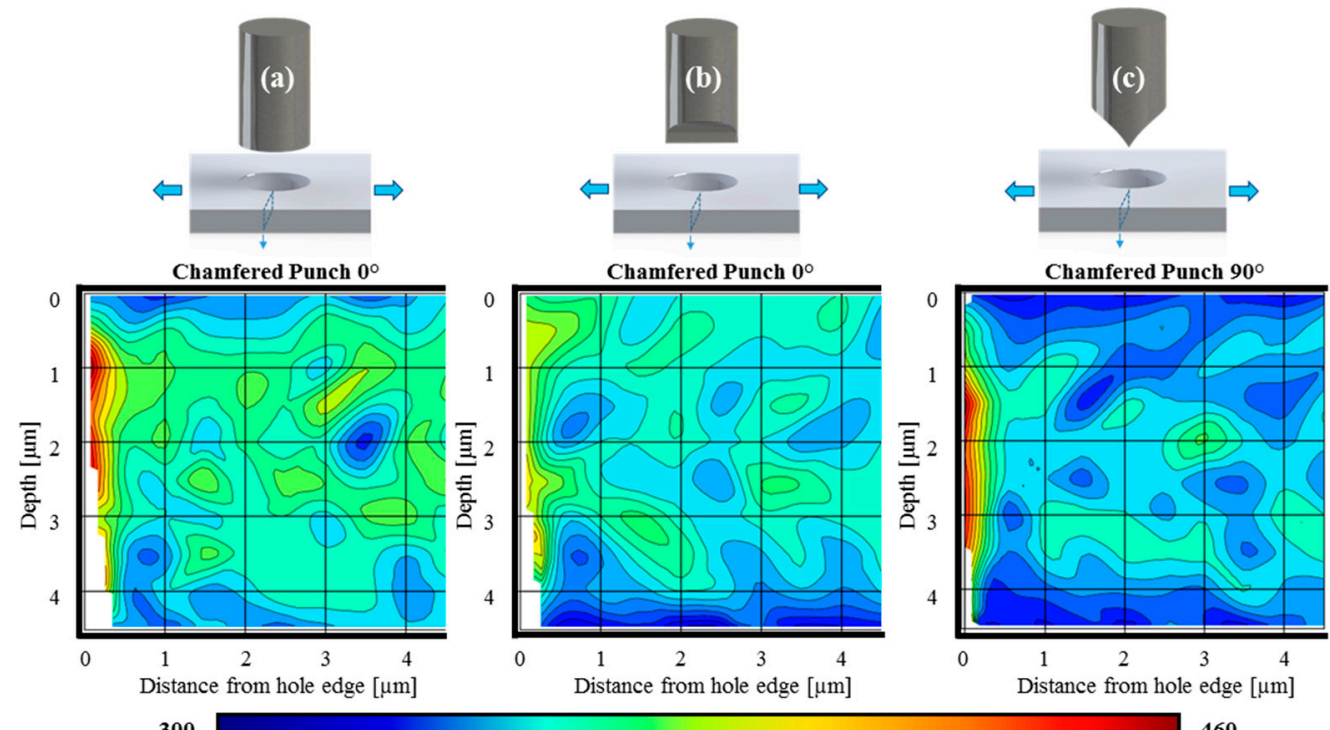

300

Chamfered Punch $0^{\circ}$

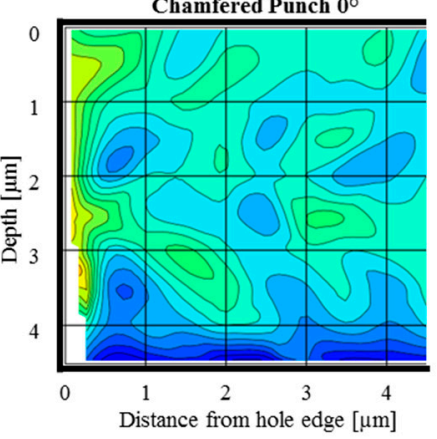

HV 0.2

Figure 12. Hardness distribution produced in the S960MC by (a) flat punch, (b) chamfered punch at $0^{\circ}$, and (c) chamfered punch at $90^{\circ}$.

(a)

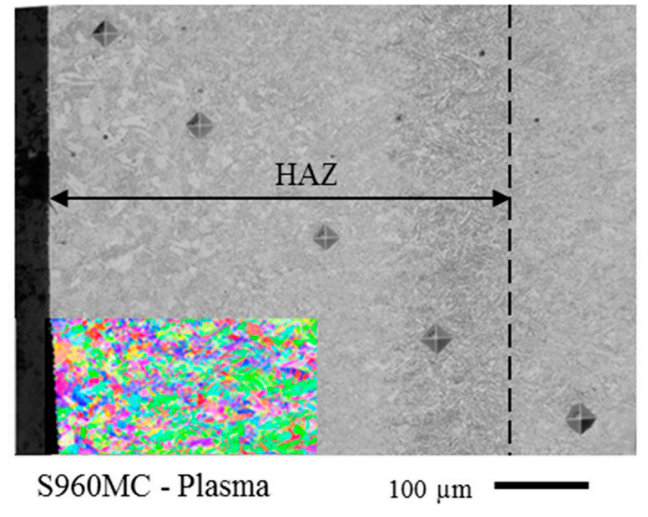

(b)

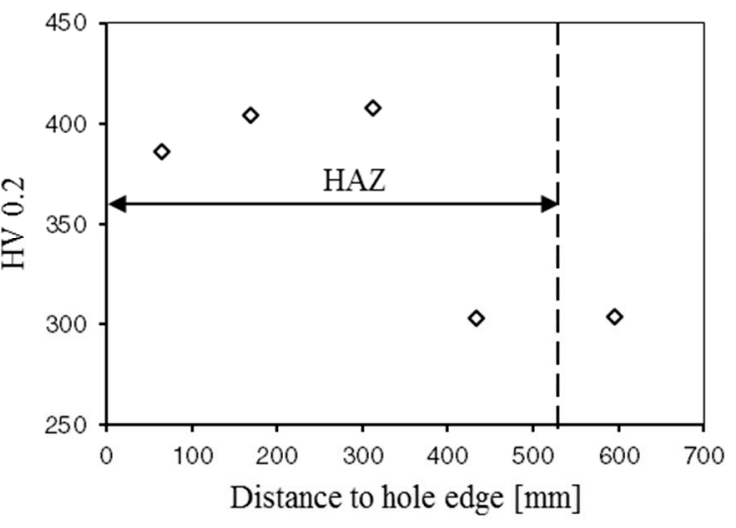

Figure 13. Hardness analysis near S960MC plasma layer: (a) micrograph displaying hardness measurements, (b) hardness values vs. distance to hole edge for each measurement.

\subsection{EBSD}

The heat-affected zone of laser-cut samples was analyzed with electron backscatter diffraction (EBSD). The hole edges of S500MC and S960MC are shown in Figure 14, measured with a step size of $0.15 \mu \mathrm{m}$. As can be seen, the hole edges were covered with a thin oxide layer followed by a thin, fine-grained zone. 

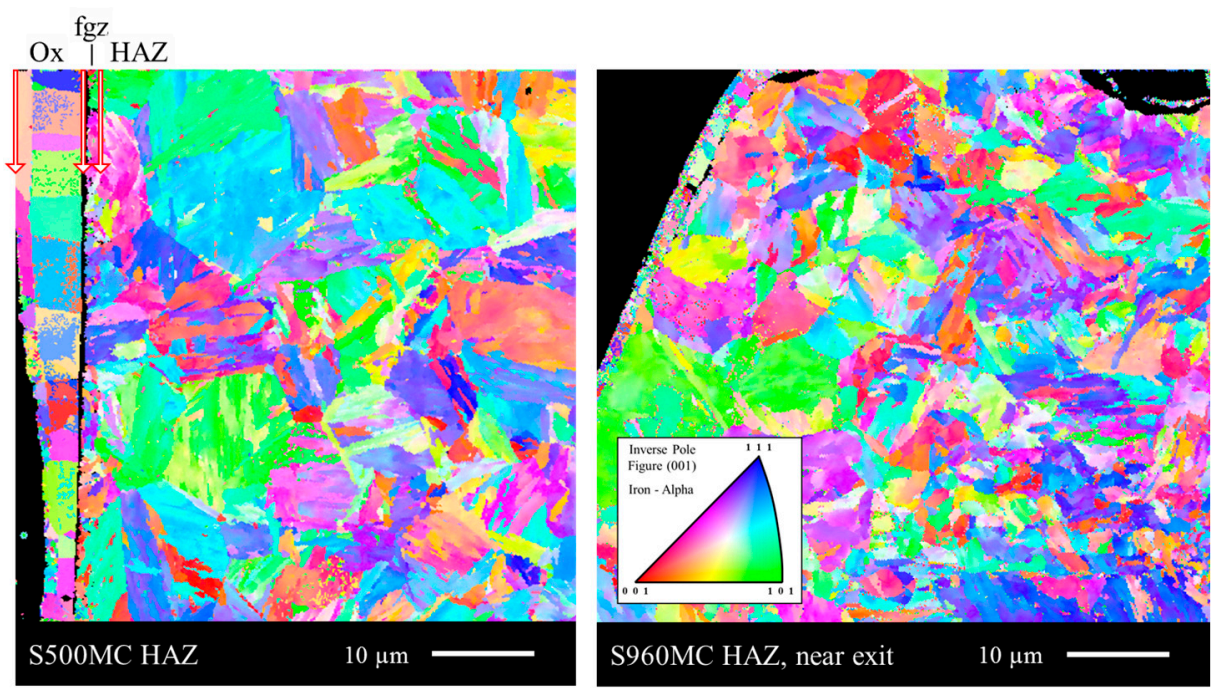

Figure 14. Hole edges of S500MC and S960MC measured with electron backscatter diffraction (EBSD). The EBSD inverse pole figure orientation map is given. The transition of different surface layers are marked with arrows in the S500MC grade: Ox, oxidation layer; fgz, fine-grained zone; HAZ, heat-affected zone.

In Figure 15 an overview of the hole edges is shown. The EBSD maps are measured with a step size of $0.50 \mu \mathrm{m}$ for the laser-cut samples and $0.25 \mu \mathrm{m}$ for the punched S960MC sample. For the S500MC grade, the transition to the ferritic microstructure is visible. To image highly deformed materials the spatial resolution needs to be smaller than the size of the dislocation cells [30]. The acquired EBSD patterns became weaker with high deformation, resulting in low confidence index values at the hole edge of the punched samples, but the transition from the base material to the deformed material is visible.
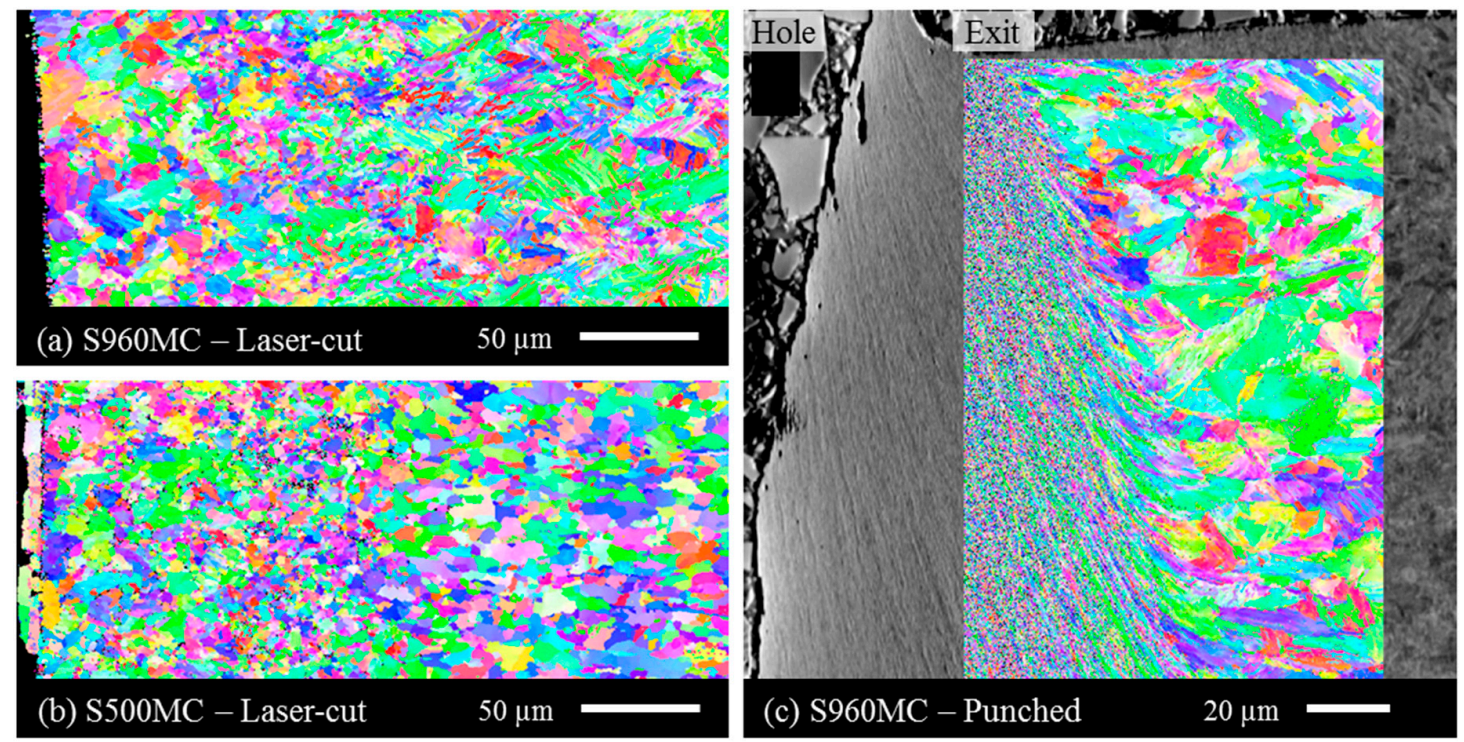

Figure 15. EBSD inverse pole figure orientation map of the two grades (a) S960MC and (b) S500MC. The laser-cut surfaces are on the left-hand side. (c) SEM image of a punched S960MC grade overlaid with an EBSD inverse pole figure orientation map. The exit side is shown on the top side.

\subsection{Residual Stress}

The results of the residual stress measurements of the punched sample in the longitudinal and the transversal direction are displayed in Figure 16a,b. Both the left and the right sides of the hole were 
measured. The measurements did not differ much and showed the same tendency. Here, only the XY side is shown. The residual stresses in longitudinal direction are, in comparison to the transversal direction, more shifted towards compressive stresses. The formation of the residual stresses during the punching process were dependent on various parameters, e.g., local plastic flow, evolution of damage, and clamping parameters, which can be reproduced and explained via simulations [31]. The highest stresses can be observed in the S960MC punched sample due to the higher flow stress of the material. The residual stresses of the laser-cut specimen in the longitudinal and transversal direction are shown in Figure 16c,d. The magnitude of the residual stresses was lower compared to punched samples and there was not such a large difference between the top and the bottom face. The residual stresses resulting from the laser cutting were, on average, larger for the S500MC. It is also important to note that, due to the difference in thickness ( $5 \mathrm{~mm}$ for the S960MC and $6 \mathrm{~mm}$ for the S500MC), the cutting parameters differed between both samples. In particular, the laser-cutting speed was 2.4 times faster for the 5-mm samples, which may result in a lower heat input and, hence, lower residual stresses around the hole.

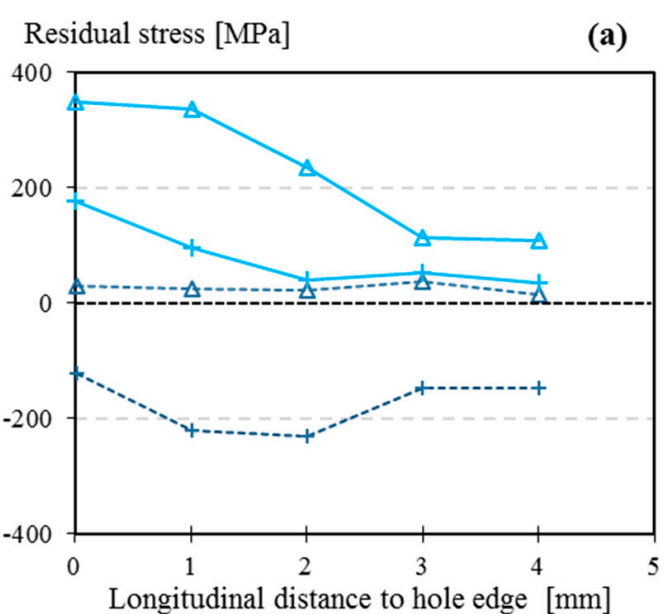

Residual stress [MPa]

(c)

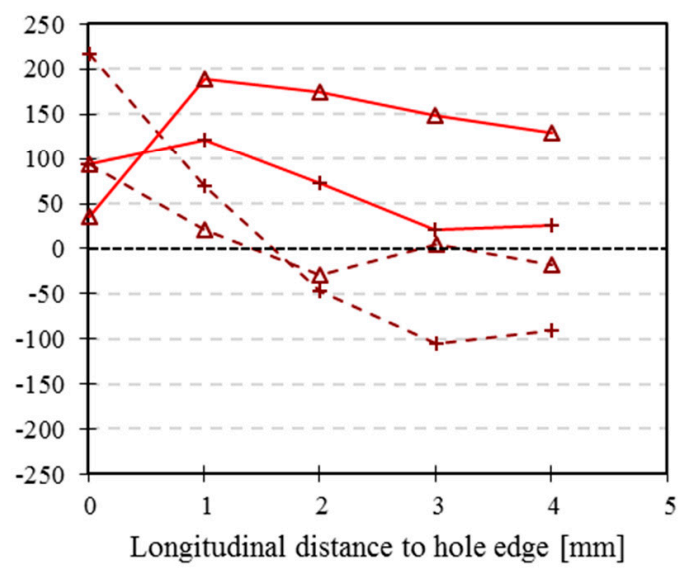

(b)

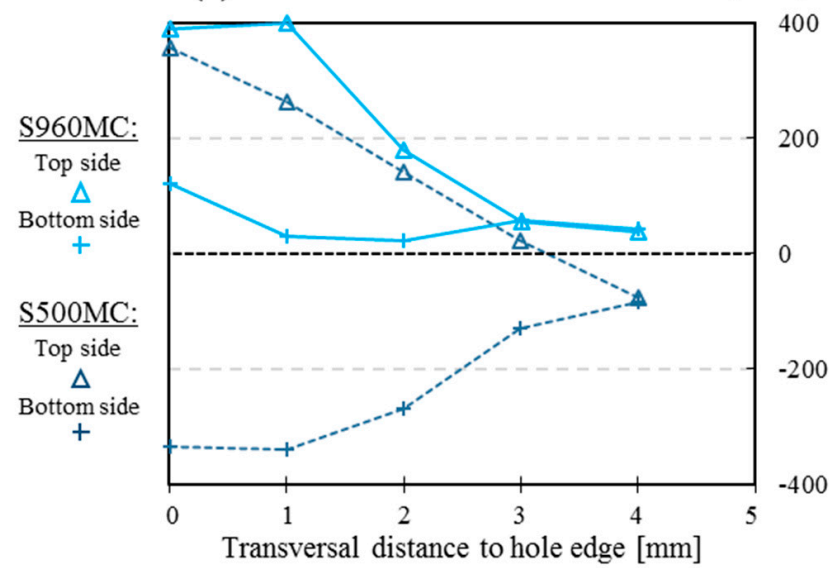

(d)

Residual stress $[\mathrm{MPa}]$

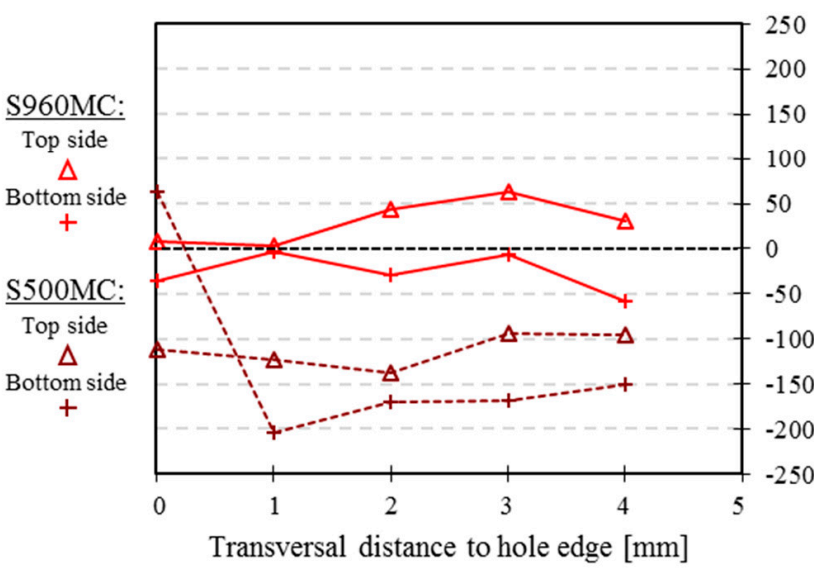

Figure 16. Residual stresses of punched S500MC and S960MC specimens in the (a) longitudinal and (b) transverse direction, and of laser-cut S500MC and S960MC specimens in the (c) longitudinal and (d) transverse direction. Here, error bars are smaller than the markers and are, therefore, not shown. Connecting lines between measurement positions are for guidance of the eye only.

\subsection{Fatigue Results}

The fatigue results for the holed specimens, tested at a nominal stress range of $300 \mathrm{MPa}$, are presented in Figure 17. The S700MC and S960MC fatigue results followed the same trend as the S500MC in [13]. Punched samples displayed the lowest fatigue performance, whereas the chamfered 
punch aligned with loading (with the sharp edge not facing the failure location) performed best among the punched samples, followed by both plasma-cut and drilled specimens, which showed a similar fatigue life. A significantly better performance was observed for waterjet-cut holes. The best fatigue performance was achieved with the laser-cut specimens, where run-out tests were found.

The difference in fatigue life for the different punch geometries related with the hardness distribution results previously presented in Section 3.5, in which the chamfered punch aligned with the load yielded lower localized cold-work hardening near the hole edge.

As in [13], failure in plasma-cut samples took place predominantly at plasma-blob locations, which did not seem to affect the number of cycles to failure. It was also found for the drilled-cut sample that the drill chip had a strong influence in the failure mechanisms and its removal resulted in run-out fatigue tests.

When the fatigue results of both HSLA grades were compared it can be noted that, although both material followed the same trend in results, S960MC had a slightly better fatigue performance than S700MC, although scarce to be statistically significant without additional testing.

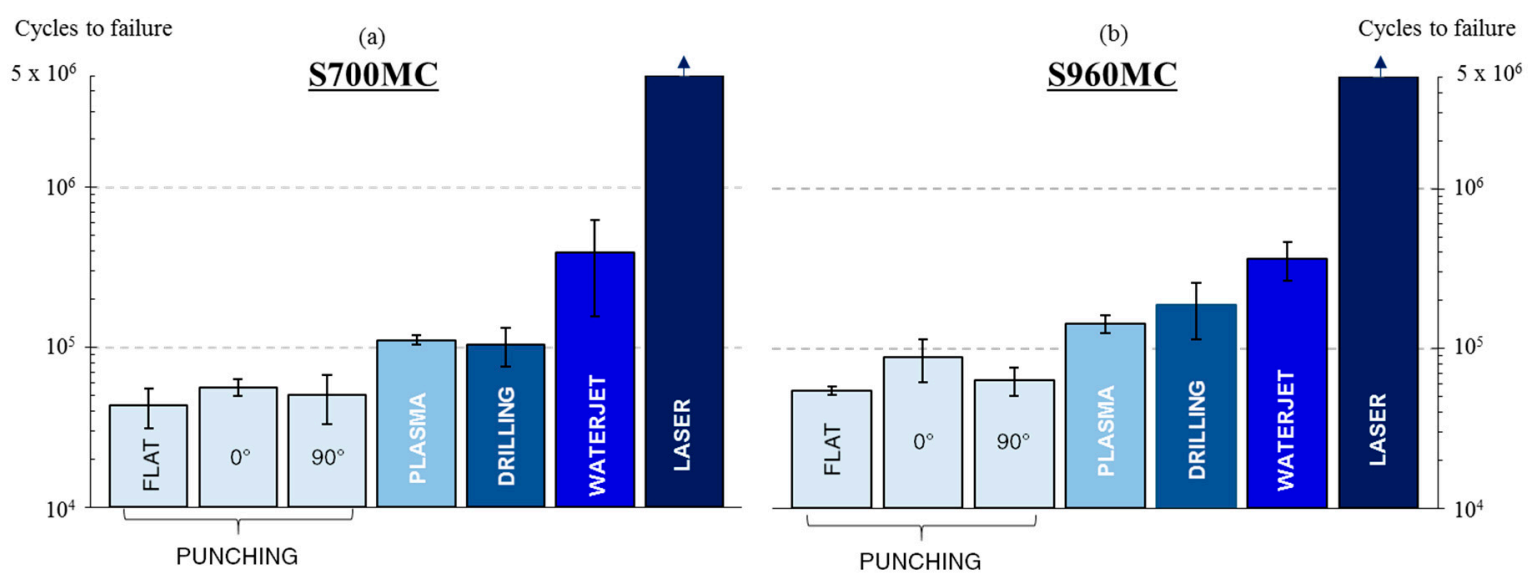

Figure 17. Fatigue results for (a) S700MC and (b) S960MC.

The presented fatigue results share many similarities with two researches performed in the framework of the Research Fund for Coal and Steel (RFCS): Coldfoss [16] and Hipercut [17]. Both research projects studied the influence of hole-making processes on the fatigue performance of steel grades with yield strength ranging from 350 to $900 \mathrm{MPa}$. Constant amplitude tests with a stress ratio of 0.1 were performed and the sample geometry also consisted of a plate with a hole located at its center. The fatigue behavior of punched specimens in the present study was compared with the punched and punched-plus-shot peened specimens in [16]. The results indicated that the fatigue performance of punched samples did not differ much at the present nominal stress range between different HSLA grades, which might indicate that the fatigue behavior was dominated by the presence of large macro defects. However, it is shown [16] that the shot-peening process treatment dramatically improved fatigue life in punched specimens. The laser-cut and plasma-cut specimens were compared with the laser-cut, plasma-cut, and oxy-fuel-cut specimens in [17]. Unlike in the present investigation, in which laser-cut specimen displayed the highest fatigue performance, the fatigue performance of laser-cut samples in [17] was significantly lower than oxy-fuel and plasma-cut samples. The authors referred to the large amount of draglines in the laser-cut edges as a reason for this lower performance.

\subsection{Fracture Analysis}

Fatigue failure typically occurred at the middle of the sample, starting from the hole edge. Fatigue cracks propagated perpendicular to the axial load direction. After a certain distance, when the cross-section was significantly reduced, ductile failure happened at the remaining connected material. 
The characteristic cup and cone shape produced by the shear deformation at $45^{\circ}$ with respect to the tensile axis was observed at the ductile failure region for most specimens.

Both the entry section and the shear cutting section of the punched holes were evaluated by SEM. Although all fractured punched specimens presented cracks along the shear cutting section, there was a significant difference between the milder grade S500MC studied in [13] and the other two grades (S700MC and S960MC). In Figure 18, the characteristic crack formation location is shown for the S700MC and the S960MC grades punched with a flat punch. The results in [13] indicated that cracks were likely to initiate from the lower end of the shear-cutting section for the S500MC grade. However, the presence of larger cracks propagating from the middle of the shear-cutting section was noted for the S700MC and the S960MC grades. As previously commented in Section 3.2, shear dimples were more frequent in the S700MC and S960MC grades, which may suggest larger damage and cracks produced during the punching process. These cracks, just as the shear dimples, would be located at the middle of the shear-cutting section and would further propagate due to the action of the induced cyclic loading. This middle area contained segregation of alloying elements, such as Mn. The alloying element segregation resulted in reduced ductility and toughness in this area, making it prone to cracking. The punched S500MC samples showed fewer dimples, which might explain why cracks tended to propagate from the lower region of the shear-cutting section.

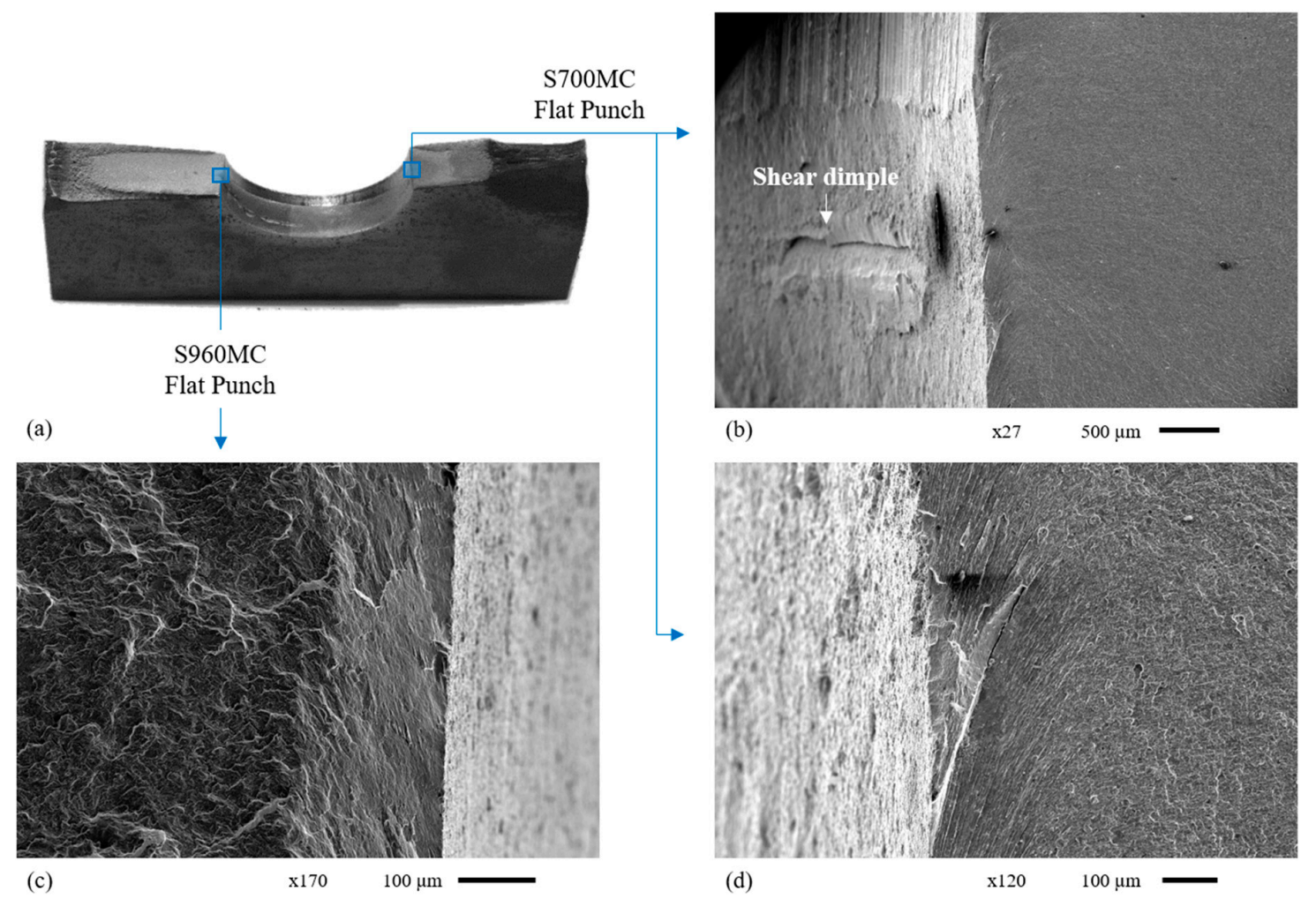

Figure 18. (a) Overview of fractured punched specimen. Fracture surfaces of flat-punched specimens: (b)(d) S700MC and (c) S960MC.

The SEM evaluation of drilled samples revealed that fracture in drilled specimens originated at the edges (top or bottom) of the hole. Both edges presented multiple sharp edges that acted as a notch during the fatigue cycles for cracks to originate and propagate. This can be observed in Figure 19a, where a crack propagated from the drill entry site to the rest of the cross-section in a S700MC specimen. The sharp edges at the entry and exit of the drill were the origin of cracks in all tested specimen and HSLA grades. Due to the high notch sensitivity of the HSLA grades, the deburring of the drilled edges was a necessary step to make the most of the smooth surface and the absence of hardening produced during drilling. 


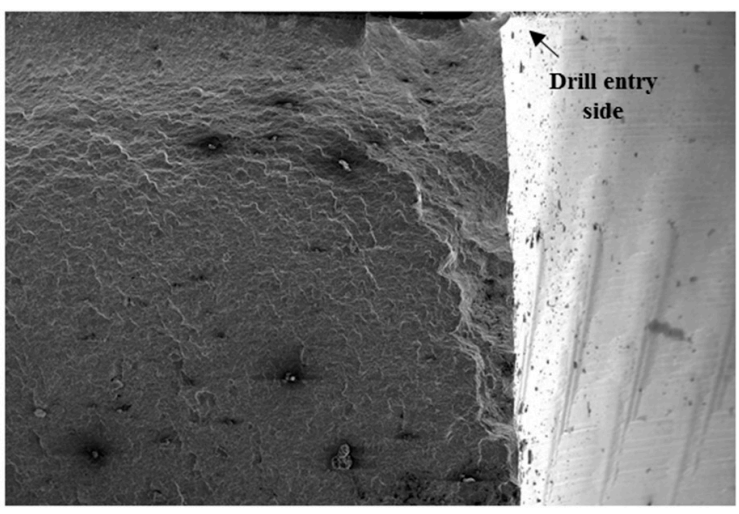

(a) $\mathrm{S} 700 \mathrm{MC}$ $\mathrm{x} 50$

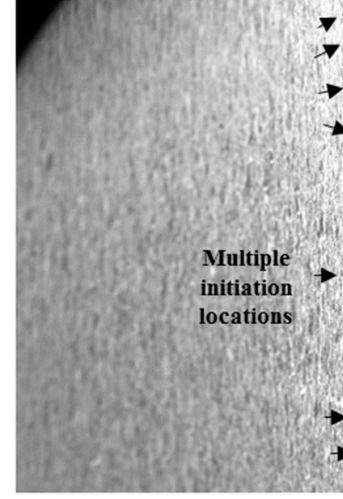

(b) S960MC

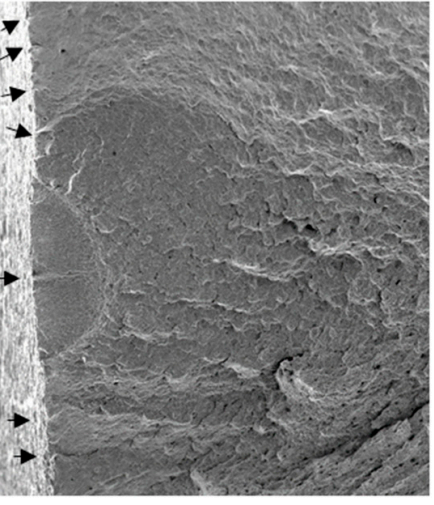

$500 \mu \mathrm{m}$

Figure 19. Fracture details of (a) entry drill chip (S760MC) and (b) waterjet-cut mid-hole surface (S960MC).

All observed waterjet-cut fractured samples were similar for all studied grades. A characteristic fractured section is shown in Figure 19b (S960MC). The waterjet-cut fractured surfaces presented multiple crack initiation sites along the hole depth, which originated from the geometrical features produced by the rough waterjet-cut surface finish, previously discussed in Section 3.2. A significant difference between waterjet-cut and punched specimens is that in the case of the first, cracks initiated from the geometrical features produced by the abrasive material while for punched specimens, cracks that were already introduced during the punching process propagated during the fatigue cycles.

The plasma blob was found to be responsible for the initiation of many of the fractured samples. As discussed in Section 3.2, the plasma blob was located at 45 degrees with respect of the hole section in which failure was expected to happen. However, due to the multiple notches induced by the plasma blob, failure occurred in this region in many of the tested specimens. As shown in Figure 20a, the plasma blob extended into the material and the pores present in the blob acted as notches for crack initiation. The surface defects produced during the plasma-cutting process were responsible for the remaining crack initiation locations. These defects were distributed along the entirety of the hole depth and their size was relatively large if compared with the defects induced during waterjet cutting, which could explain the lower performance of plasma-cut samples. An example of cracks originating from a plasma surface defect is shown in Figure 20b.

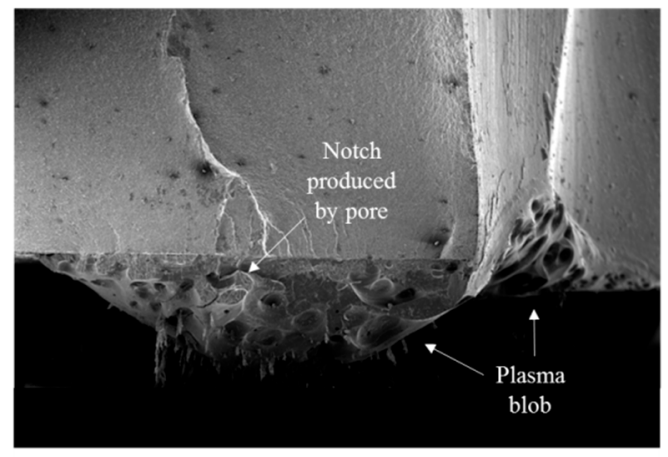

(a) $\mathrm{S} 700 \mathrm{MC}$ x 25

$500 \mu \mathrm{m}$

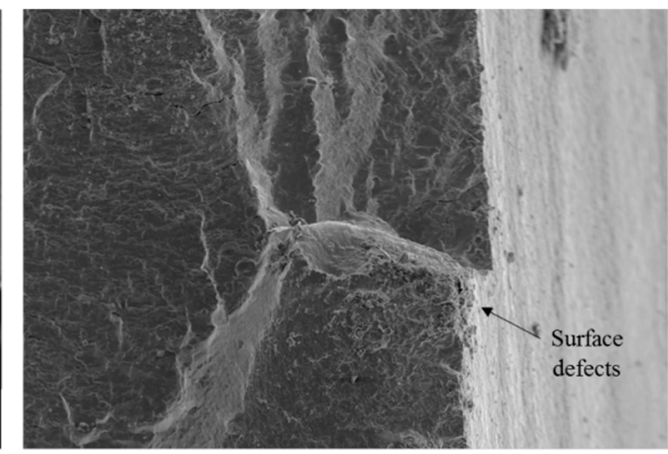

(b) $\mathrm{S} 700 \mathrm{MC}$ $\mathrm{x} 150$
$100 \mu \mathrm{m}$

Figure 20. Fracture surfaces at (a) plasma blob and (b) mid-hole surface (S700MC).

\section{Conclusions}

The results of this research provided more insight on how different hole-making procedures affect the failure mechanisms of different HSLA steel plates. It was observed that the microstructural differences between HSLA grades produced variations in the hole morphology, such as different hardening distributions, residual stresses, HAZ extension, and presence of defects. However, the higher 
yield strength of the HSLA grades did not lead to a higher fatigue life. The results of the present research on the HSLA grades S700MC and S960MC followed a similar trend as previous research performed by the authors on S500MC samples [13], with punching samples exhibiting the lowest fatigue values. This can be attributed to the high residual tensile stresses and the large amount of shear dimples and defects along the punched-hole surface. The presence of shear dimples, however, was considerably higher in the S700MC and the S960MC compared to the S500MC. Plasma samples provided similar fatigue lives to punched specimens, followed by drilled samples. Finally, waterjet cutting and laser cutting resulted in the best fatigue performing samples.

The better performance of waterjet-cut samples and laser-cut samples offers an explanation of the failure mode of the tested samples. The abrasive nature of waterjet-cut samples produced a fairly constant amount of small defects and an absence of hardening near the hole, which were not large enough to create a large stress concentration. Laser-cut samples, on the other hand, did present a significant amount of hardening and tensile residual stresses near the hole edge. However, they also exhibited an even and defect-free surface. From these observations, it seems that the fatigue performance of the holed samples was dominated by large defects inherent to each hole-making procedure, which finally resulted in a similar number of fatigue cycles for the studied HSLA grades.

Author Contributions: Conceptualization, C.J.-P. and D.D.; methodology, C.J.-P. and C.G.; validation, C.J.-P. and C.G.; formal analysis, C.J.-P., C.G. and J.P.; investigation, C.J.-P., C.G., and J.P.; resources, C.G, J.P., and D.D.; data curation, C.J.-P., and J.P.; writing-original draft preparation, C.J.-P. and C.G.; writing-review and editing, C.J.-P., C.G., J.P., and D.D.; visualization, C.J.-P.; supervision, D.D.; project administration, D.D.; funding acquisition, D.D. All authors have read and agreed to the published version of the manuscript.

Funding: This work was supported by the European Research Project DURAMECH: “Towards Best Practice for Bolted Connections in High Strength Steels" (project number 709962 [2016]) and made possible through funding support of the KU Leuven Fund for Fair Open Access.

Conflicts of Interest: The authors declare no conflict of interest.

\section{References}

1. Gogou, E. Use of High Strength Steel Grades for Economical Bridge Design. Ph.D. Thesis, TU Delft, Delft University of Technology, Delft, The Netherlands, 2012.

2. Schröter, F.; Schütz, W. State of art in the production and use of high-strength heavy plates for hydropower applications. In Proceedings of the High Strength Steel for Hydropower Plants, Graz, Austria, 5-6 July 2005.

3. Jensen, L.; Bloomstine, M.L. Application of high strength steel in super long span modern suspension bridge design. In Proceedings of the Nordic Steel Construction Conference, Stockholm, Sweden, 2-4 September 2009.

4. Miki, C.; Homma, K.; Tominaga, T. High strength and high performance steels and their use in bridge structures. J. Constr. Steel Res. 2002, 58, 3-20. [CrossRef]

5. Willms, R. High strength steel for steel constructions. In Proceedings of the Nordic Steel Construction Conference-NSCC, Malmö, Sweden, 2-4 September 2009; pp. 597-604.

6. Gresnigt, A.; Steenhuis, C. High strength steels. Prog. Struct. Eng. Mater. 1997, 1, 31-41. [CrossRef]

7. Billingham, J.; Sharp, J.; Spurrier, J.; Kilgallon, P. Review of the Performance of High Strength Steels Used Offshore; Health and Safety Executive: Bootle, UK, 2003; p. 111.

8. Bailey, N.; Coe, F.R.; Gooch, T.; Hart, P.; Jenkins, N.; Pargeter, R. Welding Steels without Hydrogen Cracking; Woodhead Publishing: Sawston, UK, 1993.

9. Tamura, I.; Sekine, H.; Tanaka, T. Thermomechanical Processing of High-Strength Low-Alloy Steels; Butterworth-Heinemann: Oxford, UK, 2013.

10. Braconi, A.; Osta, A.; Cama, P.; Blasi, N.; Mordini, A.; Wenzel, H.; Chellini, G.; Lippi, F.; Salvatore, W.; Rauert, T.; et al. Design for Optimal Performance of High-Speed Railway Bridges by Enhanced Monitoring Systems (Details); EU Publications: Bruxelles, Belgium, 2013. [CrossRef]

11. European Commission. Improving the Fatigue Life of High Strength Steel Welded Structures by Post Weld Treatments and Specific Filler Material (FATWELDHSS); Directorate-General for Research and Innovation (European Commission): Brussels, Belgium, 2010. 
12. Jiménez-Peña, C.; Talemi, R.H.; Rossi, B.; Debruyne, D. Investigations on the fretting fatigue failure mechanism of bolted joints in high strength steel subjected to different levels of pre-tension. Tribol. Int. 2017, 108, 128-140. [CrossRef]

13. Jiménez-Peña, C.; Goulas, C.; Rossi, B.; Debruyne, D. Influence of hole-making procedures on fatigue behaviour of high strength steel plates. J. Constr. Steel Res. 2019, 158, 1-14. [CrossRef]

14. Valtinat, G.; Huhn, H. Bolted connections with hot dip galvanized steel members with punched holes. In Proceedings of the Connections in Steel Structures V, Amsterdam, The Netherlands, 3-5 July 2004; pp. 297-310.

15. Goldberg, F. Influence of thermal cutting and its quality on the fatigue strength of steel. Weld. J. 1973, 52, 392-404.

16. Bannister, A.; Skalidakis, M.; Pariser, A.; Langenberg, P.; Gutierrez-Solana Salcedo, F.; Sánchez, L.; Pesquera, D.; Azpiazu, W. Performance Criteria for Cold Formed Structural Steels; EU Publications: Brussels, Belgium, 2006; pp. 1-241.

17. European Commission. High Performance Cut Edges in Structural Steel Plates for Demanding Applications (HIPERCUT); Directorate-General for Research and Innovation (European Commission): Brussels, Belgium, 2016.

18. AASHTO. AASHTO LRFD Bridge Design Specifications; Fourth Edition with 2008 Interim Revisions; American Association of State Highway and Transportation Officials: Washington, DC, USA, 2012.

19. British Standards Institution. Code of Practice for Fatigue Design and Assessment of Steel Structures; British Standards Institution: London, UK, 1993.

20. Eurocode-Basis of Structural. EN 1990: 2002-Basis of Structural Design; British Standard Institution: London, UK, 2002.

21. CEN. EN 1993-1-12. Eurocode 3: Design of Steel Structures-Part 1-12: Additional Rules for the Extension of EN 1993 Up to Steel Grades S 700; European Committee for Standardization: Brussels, Belgium, 2007.

22. Denys, K.; Coppieters, S.; Seefeldt, M.; Debruyne, D. Multi-DIC setup for the identification of a 3D anisotropic yield surface of thick high strength steel using a double perforated specimen. Mech. Mater. 2016, 100, 96-108. [CrossRef]

23. SSAB. Strenx ${ }^{\circledR} 960$ MC. Available online: https://www.ssab.com/products/brands/strenx/products/strenx960-mc?accordion=downloads (accessed on 1 December 2019).

24. Arcelormittal. Amstrong-High Strength Steels. 2018. Available online: http://industry.arcelormittal.com/ catalogue/A20/EN (accessed on 1 December 2019).

25. EN, B. 1-9 (2005): Design of Steel Structures; Part 1.9: Fatigue; British Standards Institution: London, UK, 1993.

26. VariDrill ${ }^{\mathrm{TM}}$ Catalogue. Available online: https://www.widia.com/en/products/24019771/24064245/46993284/ 100006851.html (accessed on 21 February 2019).

27. ISO, E. 6507-1: 2005-Metallic Materials-Vickers Hardness Test; European Committee for Standardization: Brussels, Belgium, 2006.

28. Prevey, P.S. X-ray diffraction residual stress techniques. Asm Int. Asm Handb. 1986, 10, 380-392.

29. Guo, F.; Wang, X.; Liu, W.; Shang, C.; Misra, R.; Wang, H.; Zhao, T.; Peng, C. The Influence of Centerline Segregation on the Mechanical Performance and Microstructure of X70 Pipeline Steel. Steel Res. Int. 2018, 89, 1800407. [CrossRef]

30. Schwartz, A.J.; Kumar, M.; Adams, B.L.; Field, D.P. Electron. Backscatter Diffraction in Materials Science; Springer: New York, NY, USA, 2000.

31. Janarthanam, H.; Sommer, S.; Carl, E.-R.; Preußner, J.; Huberth, F. Numerical prediction of damage in punching process using shear modified Gurson model. In Proceedings of the 4th European Steel Technology and Application Days, Düsseldorf, Germany, 24-28 June 2019.

(C) 2020 by the authors. Licensee MDPI, Basel, Switzerland. This article is an open access article distributed under the terms and conditions of the Creative Commons Attribution (CC BY) license (http://creativecommons.org/licenses/by/4.0/). 